\title{
COMPLETE SEMIGROUPS OF BINARY RELATIONS DEFINED BY SEMILATTICES OF THE CLASS $Z$-ELEMENTARY $X$-SEMILATTICE OF UNIONS
}

\author{
I. YASHA DIASAMIDZE, SHOTA MAKHARADZE, NEŞET AYDIN AND ALI ERDOĞAN
}

\begin{abstract}
In this paper we investigate idempotents of complete semigroups of binary relations defined by semilattices of the class $Z$-elementary $X$-semilattice of unions. For the case where $X$ is a finite set we derive formulas by calculating the numbers of idempotents of the respective semigroup.
\end{abstract}

\section{INTRODUCTION}

Let $X$ be an arbitrary nonempty set, $D$ be an $X$-semilattice of unions, i.e. a nonempty set of subsets of the set $X$ that is closed with respect to the set-theoretic operations of unification of elements from $D, f$ be an arbitrary mapping from $X$ into $D$. To each such a mapping $f$ there corresponds a binary relation $\alpha_{f}$ on the set $X$ that satisfies the condition

$$
\alpha_{f}=\bigcup_{x \in X}(\{x\} \times f(x))
$$

The set of all such $\alpha_{f}(f: X \rightarrow D)$ is denoted by $B_{X}(D)$. It is easy to prove that $B_{X}(D)$ is a semigroup with respect to the operation of multiplication of binary relations, which is called a complete semigroup of binary relations defined by an $X$-semilattice of unions $D$.

We denote by $\emptyset$ an empty binary relation or empty subset of the set $X$. The condition $(x, y) \in \alpha$ will be written in the form $x \alpha y$. Further let $x, y \in X, Y \subseteq X$, $\alpha \in B_{X}(D), T \in D, \emptyset \neq D^{\prime} \subseteq D, \breve{D}=\cup D=\bigcup_{Y \in D} Y$ and $t \in \breve{D}$. Then by symbols we denote the following sets:

$$
\begin{gathered}
y \alpha=\{x \in X \mid y \alpha x\}, Y \alpha=\bigcup_{y \in Y} y \alpha, 2^{X}=\{Y \mid Y \subseteq X\}, X^{*}=2^{X} \backslash\{\emptyset\} \\
V(D, \alpha)=\{Y \alpha \mid Y \in D\}, D_{T}^{\prime}=\left\{T^{\prime} \in D^{\prime} \mid T \subseteq T^{\prime}\right\} \\
\ddot{D}_{T}^{\prime}=\left\{T^{\prime} \in D^{\prime} \mid T^{\prime} \subseteq T\right\}, D_{t}^{\prime}=\left\{Z^{\prime} \in D^{\prime} \mid t \in Z^{\prime}\right\}, l\left(D^{\prime}, T\right)=\cup\left(D^{\prime} \backslash D_{T}^{\prime}\right) .
\end{gathered}
$$

2010 Mathematics Subject Classification. Primary 18B40; Secondary 20M14, 20M17, 20 M99. Key words and phrases. Semilattice, semigroup, binary relation.

Copyright (c) 2015 by ANUBiH. 
By symbol $\wedge\left(D, D^{\prime}\right)$ we mean an exact lower bound of the set $D^{\prime}$ in the semilattice $D$.

Definition 1.1. Let $\alpha \in B_{X}(D)$. If $\alpha \circ \alpha=\alpha$, then $\alpha$ is called an idempotent element of the semigroup $B_{X}(D)$.

Definition 1.2. We say that a complete $X$-semilattice of unions $D$ is an $X I$-semilattice of unions if it satisfies the following two conditions:

a) $\wedge\left(D, D_{t}\right) \in D$ for any $t \in \breve{D}$;

b) $Z=\bigcup_{t \in Z} \wedge\left(D, D_{t}\right)$ for any nonempty $Z$ element of $D$.

Definition 1.3. Let $D$ be an arbitrary complete $X$-semilattice of unions, $\alpha \in$ $B_{X}(D)$ and $Y_{T}^{\alpha}=\{x \in X \mid x \alpha=T\}$. If

$$
V[\alpha]= \begin{cases}V\left(X^{*}, \alpha\right), & \text { if } \emptyset \notin D, \\ V\left(X^{*}, \alpha\right), & \text { if } \emptyset \in V\left(X^{*}, \alpha\right), \\ V\left(X^{*}, \alpha\right) \cup\{\emptyset\}, & \text { if } \emptyset \notin V\left(X^{*}, \alpha\right) \text { and } \emptyset \in D,\end{cases}
$$

then it is obvious that any binary relation $\alpha$ of a semigroup $B_{X}(D)$ can always be written in the form $\alpha=\bigcup_{T \in V[\alpha]}\left(Y_{T}^{\alpha} \times T\right)$. In the sequel, such a representation of a binary relation $\alpha$ will be called quasinormal.

Note that for a quasinormal representation of a binary relation $\alpha$, not all sets $Y_{T}^{\alpha}(T \in V[\alpha])$ can be different from the empty set. But for this representation the following conditions are always fulfilled:

a) $Y_{T}^{\alpha} \cap Y_{T^{\prime}}^{\alpha}=\emptyset$, for any $T, T^{\prime} \in D$ and $T \neq T^{\prime}$;

b) $X=\bigcup_{T \in V[\alpha]} Y_{T}^{\alpha}$.

Lemma 1.4. [2, Equality 6.9] Let $Y=\left\{y_{1}, y_{2}, \ldots, y_{k}\right\}$ and $D_{j}=\left\{T_{1}, T_{2}, \ldots, T_{j}\right\}$ be sets, where $k \geq 1$ and $j \geq 1$. Then the number $s(k, j)$ of all possible mappings of the set $Y$ on any such subset of the set $D_{j}^{\prime}$ such that $T_{j} \in D_{j}^{\prime}$ can be calculated by the formula $s(k, j)=j^{k}-(j-1)^{k}$.

Lemma 1.5. Let $D_{j}=\left\{T_{1}, T_{2}, \ldots, T_{j}\right\}, X$ and $Y$ be three such sets, that $\emptyset \neq Y \subseteq$ $X$. If $f$ is such mapping of the set $X$, in the set $D_{j}$, for which $f(y)=T_{j}$ for some $y \in Y$, then the number $s$ of all those mappings $f$ of the set $X$ in the set $D_{j}$ is equal to $s=j^{|X \backslash Y|} \cdot\left(j^{|Y|}-(j-1)^{|Y|}\right)$.

Proof. Let $f_{1}$ be a mappings of the set $X \backslash Y$ in the set $D_{j}$, then the number of all such mappings is equal to $j^{|X \backslash Y|}$.

Now let $f_{2}$ be all mappings of the set $Y$ in the set $D_{j}$, for which $f(y)=T_{j}$ for some $y \in Y$, then by Lemma 1.4 the number of all such mappings is equal to $j^{|Y|}-(j-1)^{|Y|}$.

We define the mapping $f$ of the set $X$ in the set $D_{j}$ by

$$
f(x)= \begin{cases}f_{1}(x) & \text { if } x \in X \backslash Y \\ f_{2}(x) & \text { if } x \in Y\end{cases}
$$

It is clear that the mapping $f$ satisfies all the conditions of the given Lemma. 
Thus the number $s$ of all such maps is equal to all number of the pair $\left(f_{1}, f_{2}\right)$. The number all such pair is equal to $s=j^{|X \backslash Y|} \cdot\left(j^{|Y|}-(j-1)^{|Y|}\right)$.

The following Theorems are well known (see, $[1,2,3,4,5,6])$.

Theorem 1.6. [2, Theorem 2.1] A binary relation $\alpha \in B_{X}(D)$ is a right unit of this semigroup iff $\alpha$ is idempotent and $D=V(D, \alpha)$.

Theorem 1.7. [2, Theorem 2.6] Let $D$ be a complete $X$-semilattice of unions. The semigroup $B_{X}(D)$ possesses a right unit iff $D$ is an $X I$-semilattice of unions.

Theorem 1.8. [1, Theorem 6.2.3], [5, Theorem 6] Let $D, \Sigma(D), E_{X}^{(r)}(Q)$ and $I_{D}$ denote respectively the complete $X$-semilattice of unions, the set of all $X I$ subsemilattices of the semilattice $D$, the set of all right units of the semigroup $B_{X}(Q)$ and the set of all idempotents of the semigroup $B_{X}(D)$. Then for the sets $E_{X}^{(r)}(Q)$ and $I_{D}$ the following statements are true:

a) If $\emptyset \in D$ and $\Sigma_{\emptyset}(D)=\left\{D^{\prime} \in \Sigma(D) \mid \emptyset \in D^{\prime}\right\}$ then

(1) $E_{X}^{(r)}(Q) \cap E_{X}^{(r)}\left(Q^{\prime}\right)=\emptyset$ for any elements $Q$ and $Q^{\prime}$ of the set $\Sigma_{\emptyset}(D)$ that satisfy the condition $Q \neq Q^{\prime}$;

(2) $I_{D}=\bigcup_{Q \in \Sigma_{\emptyset}(D)} E_{X}^{(r)}(Q)$;

(3) The equality $\left|I_{D}\right|=\sum_{Q \in \Sigma_{\emptyset}(D)}\left|E_{X}^{(r)}(Q)\right|$ is fulfilled for the finite set $X$.

b) If $\emptyset \notin D$, then

(1) $E_{X}^{(r)}(Q) \cap E_{X}^{(r)}\left(Q^{\prime}\right)=\emptyset$ for any elements $Q$ and $Q^{\prime}$ of the set $\Sigma(D)$ that satisfy the condition $Q \neq Q^{\prime}$;

(2) $I_{D}=\bigcup_{Q \in \Sigma(D)} E_{X}^{(r)}(Q)$;

(3) The equality $\left|I_{D}\right|=\sum_{Q \in \Sigma(D)}\left|E_{X}^{(r)}(Q)\right|$ is fulfilled for the finite set $X$.

Theorem 1.9. [3] Let $D=\left\{\breve{D}, Z_{1}, Z_{2}, \ldots, Z_{n-1}\right\}$ be some finite $X$-semilattice of unions and $C(D)=\left\{P_{0}, P_{1}, \ldots, P_{n-1}\right\}$ be the family of sets of pairwise nonintersecting subsets of the set $X$. If $\varphi$ is a mapping of the semilattice $D$ on the family of sets $C(D)$ which satisfies the condition $\varphi(\breve{D})=P_{0}$ and $\varphi\left(Z_{i}\right)=P_{i}$ for any $i=1,2, \ldots, n-1$ and $\hat{D}_{Z}=D \backslash\{T \in D \mid Z \subseteq T\}$, then the following equalities are valid:

$$
\breve{D}=P_{0} \cup P_{1} \cup \cdots \cup P_{n-1}, Z_{i}=P_{0} \cup \bigcup_{T \in \hat{D}_{Z_{i}}} \varphi(T) .
$$

In the sequel these equalities will be called formal.

It is proved that if the elements of the semilattice $D$ are represented in the form $(*)$, then among the parameters $P_{i}(i=1,2, \ldots, n-1)$ there exists a parameter that cannot be empty sets for $D$. Such sets $P_{i}(0<i \leq n-1)$ are called basis sources, whereas sets $P_{i}(0 \leq j \leq n-1)$ which can be empty sets too are called completeness sources.

It is proved that under the mapping $\varphi$ the number of covering elements of the pre-image of a basis source is always equal to one, while under the mapping $\varphi$ the 
number of covering elements of the pre-image of a completeness source either does not exist or is always greater than one (see, [[3]]).

Lemma 1.10. Let $D=\left\{\breve{D}, Z_{1}, Z_{2}, \ldots, Z_{n-1}\right\}$ and $C(D)=\left\{P_{0}, P_{1}, \ldots, P_{n-1}\right\}$ be the finite semilattice of unions and the family of sets of pairwise nonintersecting subsets of the set $X ; \varphi=\left(\begin{array}{ccccc}\breve{D} & Z_{1} & Z_{2} & \ldots & Z_{n-1} \\ P_{0} & P_{1} & P_{2} & \ldots & P_{n-1}\end{array}\right)$ is a mapping of the semilattice $D$ on the family of sets $C(D)$. If $\varphi(T)=P \in C(D)$ for some $\breve{D} \neq T \in D$, then $D_{t}=D \backslash \ddot{D}_{T}$ for all $t \in P$.

Proof. Let $t$ and $Z^{\prime}$ be any elements of the set $P\left(P \neq P_{0}\right)$ and of the semilattice $D$ respectively. Then the equality $P \cap Z^{\prime}=\emptyset$ (i.e., $Z^{\prime} \notin D_{t}$ for any $t \in P$ ) is valid if and only if $T \notin \hat{D}_{Z^{\prime}}$ (if $T \in \hat{D}_{Z^{\prime}}$, then $\varphi(T) \subseteq Z^{\prime}$ by definition of the formal equalities of the semilattice $D)$. Since $\hat{D}_{Z^{\prime}}=D \backslash\left\{T^{\prime} \in D \mid Z^{\prime} \subseteq T^{\prime}\right\}$ by definition of the set $\hat{D}_{Z^{\prime}}$. Thus the condition $T \notin \hat{D}_{Z^{\prime}}$ hold iff $T \in\left\{T^{\prime} \in D \mid Z^{\prime} \subseteq T^{\prime}\right\}$. So, $Z^{\prime} \subseteq T$ and $Z^{\prime} \in \ddot{D}_{T}$ by definition of the set $\ddot{D}_{T}$.

Therefore, $\varphi(T) \cap Z^{\prime}=\emptyset$ if and only if $Z^{\prime} \in \ddot{D}_{T}$. Of this follows that the inclusion $\varphi(T)=P \subseteq Z^{\prime}$ is true iff $D_{t}=D \backslash \ddot{D}_{T}$ for all $t \in \varphi(T)=P$.

\section{Results}

Definition 2.1. Let $D$ be complete $X$-semilattice of unions and $Z$ be some fixed element of $D$. We say that a complete $X$-semilattice of unions $D$ is $Z$-elementary if $D$ satisfies the following conditions:

a) $D$ is not a chain;

b) every subchain of the semilattice $D$ is finite;

c) the set $D_{Z}=\{T \in D \mid Z \subseteq T\}$ is a chain with smallest element $Z$;

d) the condition $T \cup T^{\prime}=Z$ holds for any incomparable elements $T$ and $T^{\prime}$ of D.

Example 1. The diagrams 1, 2, 3, 4 of the Fig. 2.1 respectively are $Z_{1}, \breve{D}, Z_{1}$ and $Z_{2}$ elementary $X$-semilattices of unions:

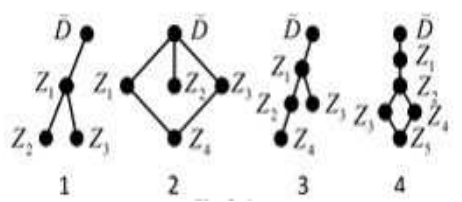

Fig. 2.1

Lemma 2.2. If $D$ is $Z$-elementary $X$-semilattice of unions, then $D \backslash\{Z\}$ is unique generated set of the semilattice $D$.

Proof. The given Lemma immediately follows from the $Z$-elementary $X$-semilattice of unions. 
Lemma 2.3. Let $D$ be $Z$-elementary $X$-semilattice of unions. If subsemilattice $D^{\prime}$ of the semilattice $D$ is not a chain, then $D^{\prime}$ is $Z$-elementary $X$-semilattice of unions.

Proof. Let $D$ be $Z$-elementary $X$-semilattice of unions. Suppose that the subsemilattice $D^{\prime}$ of the semilattice $D$ is not a chain.

1) It is clear, that the length of any chain of the semilattice $D^{\prime}$ is finite since $D^{\prime} \subseteq D$.

2) If $T \in D_{Z}^{\prime} \backslash\{Z\}$, then $T \in D_{Z}$ since $T \in D^{\prime} \subseteq D, Z \subset T$. We have $D_{Z}^{\prime} \subseteq D_{Z}$. Therefore, it follows that $D_{Z}^{\prime}$ is a chain.

3) Further, let $T$ and $T^{\prime}$ be such elements of the set $D^{\prime}$ such that $T \backslash T^{\prime} \neq \emptyset$ and $T^{\prime} \backslash T \neq \emptyset$ (i.e., the elements $T$ and $T^{\prime}$ of $D$ are incomparable). Then $T, T^{\prime} \in D$, since $D^{\prime} \subseteq D$. From this we have $T \cup T^{\prime}=Z$ by the definition of the $Z$-elementary $X$-semilattice union $D$.

From the conditions (1), (2) and (3) it follows, that $D^{\prime}$ is $Z$-elementary $X$-semilattice of unions.

Definition 2.4. Let $C$ and $C^{\prime}$ be finite different chains of the set $2^{X}$ and $Z \in C \cap C^{\prime}$. We say that the chains $C$ and $C^{\prime}$ are $Z$-compatible if $C$ and $C^{\prime}$ satisfy the following conditions:

a) $T \cup T^{\prime}=Z$ for any $T \in C \backslash C^{\prime}$ and $T^{\prime} \in C^{\prime} \backslash C$;

b) if $\bar{C}_{Z}=\{T \in C \mid Z \subseteq T\}$ and $\bar{C}_{Z}^{\prime}=\left\{T^{\prime} \in C^{\prime} \mid Z \subseteq T^{\prime}\right\}$, then $\bar{C}_{Z}=\bar{C}_{Z}^{\prime}$ (see diagram 1 and 2 of the Fig.2.2).

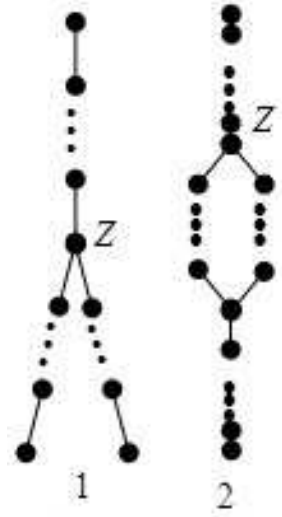

Fig. 2.2

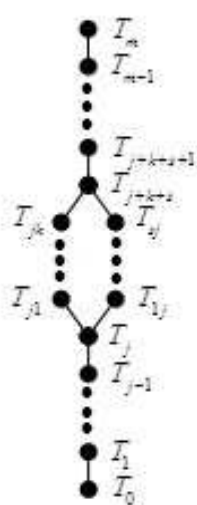

Fig. 2.3

Definition 2.5. The chain $C$ of a $X$-semilattice of unions $D$ is called maximal, if the inclusion $C \subseteq C^{\prime}$ implies that $C=C^{\prime}$ for any chain $C^{\prime}$ of the $X$-semilattice of unions $D$.

Theorem 2.6. Suppose $X$-semilattice of unions $D$ is not a chain. Then $D$ is $Z$-elementary $X$-semilattice of unions iff any two maximal subchain of the $X$-semilattice of unions $D$ are $Z$-compatible. 
Proof. Let $D$ be $Z$-elementary $X$-semilattice of unions and $C, C^{\prime}$ be two different maximal subchains of the $X$-semilattice of unions $D$.

a) Let $\bar{C}_{Z}=\{T \in C \mid Z \subseteq T\}, \bar{C}_{Z}^{\prime}=\left\{T^{\prime} \in C^{\prime} \mid Z \subseteq T^{\prime}\right\}$. By assumption the sets $\bar{C}_{Z}, \bar{C}_{Z}^{\prime}$ and $D_{Z}$ are maximal chains of the $X$-semilattice of union $D$ with smallest element $Z$. Then $D_{Z}=\bar{C}_{Z}=\bar{C}_{Z}^{\prime}$ since by definition of the $Z$-elementary $X$-semilattice of unions $D$ the maximal subchains $D_{Z}, \bar{C}, \bar{C}^{\prime}$ of the $X$-semilattice $D$, with the smallest element $Z$ are by definition unique.

b) Let $T \in C \backslash C^{\prime}$ and $T^{\prime} \in C^{\prime} \backslash C$. Then $T \subset Z, T^{\prime} \subset Z$ and $T \neq T^{\prime}$. If $T \backslash T^{\prime} \neq \emptyset$ and $T^{\prime} \backslash T \neq \emptyset$ then $T \cup T^{\prime}=Z$ by definition of the semilattice $D$. Therefore, the chains $C$ and $C^{\prime}$ are $Z$-compatible.

1) So, we can assumed that $T \backslash T^{\prime}=\emptyset$ and $T^{\prime} \backslash T \neq \emptyset$. Further, let the element $T^{\prime}$ cover the element $T_{1}^{\prime}$ in the chain $C^{\prime}$. Then $T_{1}^{\prime} \backslash T \neq \emptyset$ or $T_{1}^{\prime} \backslash T=\emptyset$. If $T_{1}^{\prime} \backslash T \neq \emptyset$, then we have $T^{\prime} \backslash T \supset T_{1}^{\prime} \backslash T \neq \emptyset$. But the inequality $T^{\prime} \backslash T \neq \emptyset$ contradicts the equality $T \backslash T^{\prime}=\emptyset$. So, $T_{1}^{\prime} \backslash T=\emptyset$.

2) Let $T_{1}^{\prime} \backslash T=\emptyset$. Then $T \supset T_{1}^{\prime}$ and continue this process we obtain $T \supset T_{1}^{\prime} \supset$ $T_{2}^{\prime} \supset \cdots \supset T_{q}^{\prime}$ and $T_{q}^{\prime} \backslash T=\emptyset$, where $T, T_{1}^{\prime}, T_{2}^{\prime}, \cdot, T_{q}^{\prime} \in C^{\prime}$ and element $T_{i}^{\prime}$ cover the element $T_{i+1}^{\prime}(i=1,2, \ldots, q-1)$. But, this process must stop, since the chains $C^{\prime}$ is finite. So, there exists a natural number $s$, such that $T \supset T_{1}^{\prime} \supset T_{2}^{\prime} \supset \cdots \supset T_{s}^{\prime}$ and $T_{s}^{\prime} \backslash T \neq \emptyset$. We have $T^{\prime} \backslash T \supset T_{1}^{\prime} \backslash T \supset T_{2}^{\prime} \backslash T \supset \cdots \supset T_{s}^{\prime} \backslash T$, i.e., $T^{\prime} \backslash T \neq \emptyset$. We have $T^{\prime} \backslash T \neq \emptyset, T \backslash T^{\prime} \neq \emptyset$ and $T^{\prime} \cup T=Z$ by definition of the $Z$-elementary $X$-semilattice of unions $D$. So, $T \cup T^{\prime}=Z$ for any $T \in C \backslash C^{\prime}$ and $T^{\prime} \in C^{\prime} \backslash C$.

Therefore, the chains are compatible.

Let any two maximal subchains of the $X$-semilattice of unions $D$ be $Z$-compatible. Then we have:

1) By supposition $D$ is not a chain.

2) Every subchain of the semilattice $D$ is finite, since all $Z$-comparable chains are finite.

3) By the definition of $Z$-comparable chains, the set $D_{Z}=\{T \in D \mid Z \subseteq T\}$ is a chain with smallest element $Z$;

4) If $T$ and $T^{\prime}$ are any incomparable elements of $D$, then there exist two maximal different chains $C$ and $C^{\prime}$ such that $T \in C \backslash C^{\prime}, T^{\prime} \in C^{\prime} \backslash C$ and the chains $C$ and $C^{\prime}$ are $Z$-compatible, then $T \cup T^{\prime}=Z$.

Let $D$ be $Z$-elementary $X$-semilattice of unions and

$$
Q=\left\{T_{0}, T_{1}, \ldots, T_{j-1}, T_{j}, T_{j+1}, \ldots, T_{k-1}, T_{k}, T_{k+1}, \ldots, T_{m-1}, T_{m}\right\}
$$

be an $X I$-subsemilattice of the $Z$-elementary $X$-semilattice of unions $D$ which satisfy the following conditions:

$$
\begin{aligned}
& T_{0} \subset T_{1} \subset \cdots \subset T_{j-1} \subset T_{j} \subset T_{j+1} \subset \cdots \subset T_{k-2} \subset T_{k} \subset T_{k+1} \subset \cdots \subset T_{m-1} \subset T_{m}, \\
& \cdots \cdots \cdots \cdots \cdots \cdots \cdots \cdots \cdots \cdots \cdots \cdots \cdots \cdots \cdots \cdots \cdots \cdots \cdots \cdots T_{m-1} \subset T_{m}, \\
& T_{0} \subset T_{1} \subset \cdots T_{j-1} \subset T_{j} \subset T_{j+2} \subset \cdots \subset T_{k-1} \subset T_{k} \subset T_{k+1} \subset \cdots \subset T_{m} \subset \cdots, T_{s j} \backslash T_{j k} \neq \emptyset, T_{j k} \cup T_{s j}=T_{j+k+s} .
\end{aligned}
$$


(i.e., the number different elements covered by the element $Z$ is two). Note that the diagram of the semilattice $D$ is shown in Fig. 2.3.

Further, let

$$
\begin{aligned}
C(Q) & =\left\{P_{i} \mid i=0,1, \ldots, j, j+k+s, j+k+s+1, \ldots m-1, m\right\} \\
& \cup\left\{P_{j 1}, \ldots, P_{j k}\right\} \cup\left\{P_{1 j}, \ldots, P_{s j}\right\}
\end{aligned}
$$

be a family of sets, where every two elements are pairwise disjoint subsets of the set $X$,

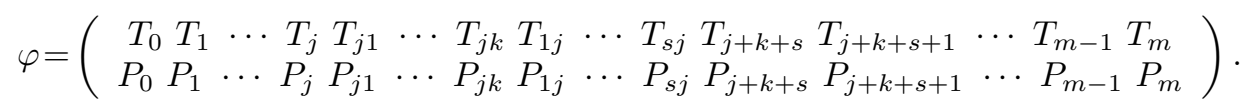

Then for the formal equalities of the semilattice $Q$ we have :

$$
\begin{aligned}
& T_{m}=P_{m} \cup P_{m-1} \cup \cdots \cup P_{j+k+s+1} \cup P_{j+k+s} \cup P_{s j} \cup \cdots \cup P_{1 j} \cup P_{j k} \cup \cdots \cup P_{j 1} \\
& \cup P_{j} \cup \cdots \cup P_{1} \cup P_{0} \\
& T_{m}=P_{m} \cup P_{m-2} \cup \cdots \cup P_{j+k+s+1} \cup P_{j+k+s} \cup P_{s j} \cup \cdots \cup P_{1 j} \cup P_{j k} \cup \cdots \cup P_{j 1} \\
& \cup P_{j} \cup \cdots \cup P_{1} \cup P_{0} \\
& \vdots \\
& T_{j+k+s+1}=P_{m} \cup P_{j+k+s} \cup P_{s j} \cup \cdots \cup P_{1 j} \cup P_{j k} \cup \cdots \cup P_{j 1} \cup P_{j} \cup \cdots \cup P_{1} \cup P_{0} \\
& T_{j+k+s}=P_{m} \cup P_{s j} \cup \cdots \cup P_{1 j} \cup P_{j k} \cup \cdots \cup P_{j 1} \cup P_{j} \cup \cdots \cup P_{1} \cup P_{0} \\
& T_{j k}=P_{m} \cup P_{s j} \cup \cdots \cup P_{1 j} \cup P_{j k} \cup \cdots \cup P_{j 1} \cup P_{j} \cup \cdots \cup P_{1} \cup P_{0} \\
& T_{s j}=P_{m} \cup P_{s-1 j} \cup \cdots \cup P_{1 j} \cup P_{j k} \cup \cdots \cup P_{j 1} \cup P_{j} \cup \cdots \cup P_{1} \cup P_{0} \\
& \vdots \\
& T_{j 1}=P_{m} P_{s j} \cup \cdots \cup P_{1 j} \cup P_{j k} \cup \cdots \cup P_{j 1} \cup P_{j} \cup \cdots \cup P_{1} \cup P_{0} \\
& T_{1 j}=P_{m} \cup P_{j k} \cup \cdots \cup P_{j 1} \cup P_{j} \cup \cdots \cup P_{1} \cup P_{0} \\
& \vdots \\
& T_{1}=P_{m} \cup P_{0} \\
& T_{1}=P_{m}
\end{aligned}
$$

Here the elements $P_{0}, P_{1}, \ldots, P_{j-1}, P_{j 1}, \ldots, P_{j k}, P_{1 j}, \ldots, P_{s j}, P_{j+k+s}, P_{j+k+s+1}$, $\ldots, P_{m-1}$ are basis sources, the elements $P_{j}, P_{m}$ are sources of completeness of the semilattice $Q$.

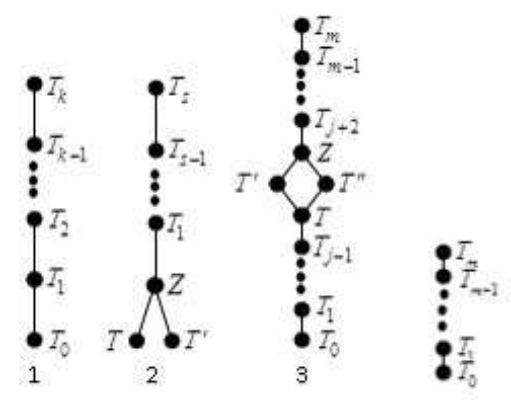

Fig. $2.4 \quad$ Fig. 2.5 
Lemma 2.7. Let $Q$ be a semilattice, whose diagram is shown in Fig.2.3. Then $Q$ is a XI-semilattice of unions if and only if $k=s=1$.

Proof. Let $t \in \breve{Q}, Q_{t}=\{Z \in Q \mid t \in Z\}$ and $\wedge\left(Q, Q_{t}\right)$ be the exact lower bound of the set $Q_{t}$ in $Q$. Then from the formal equalities and by Lemma 1.10 we have:

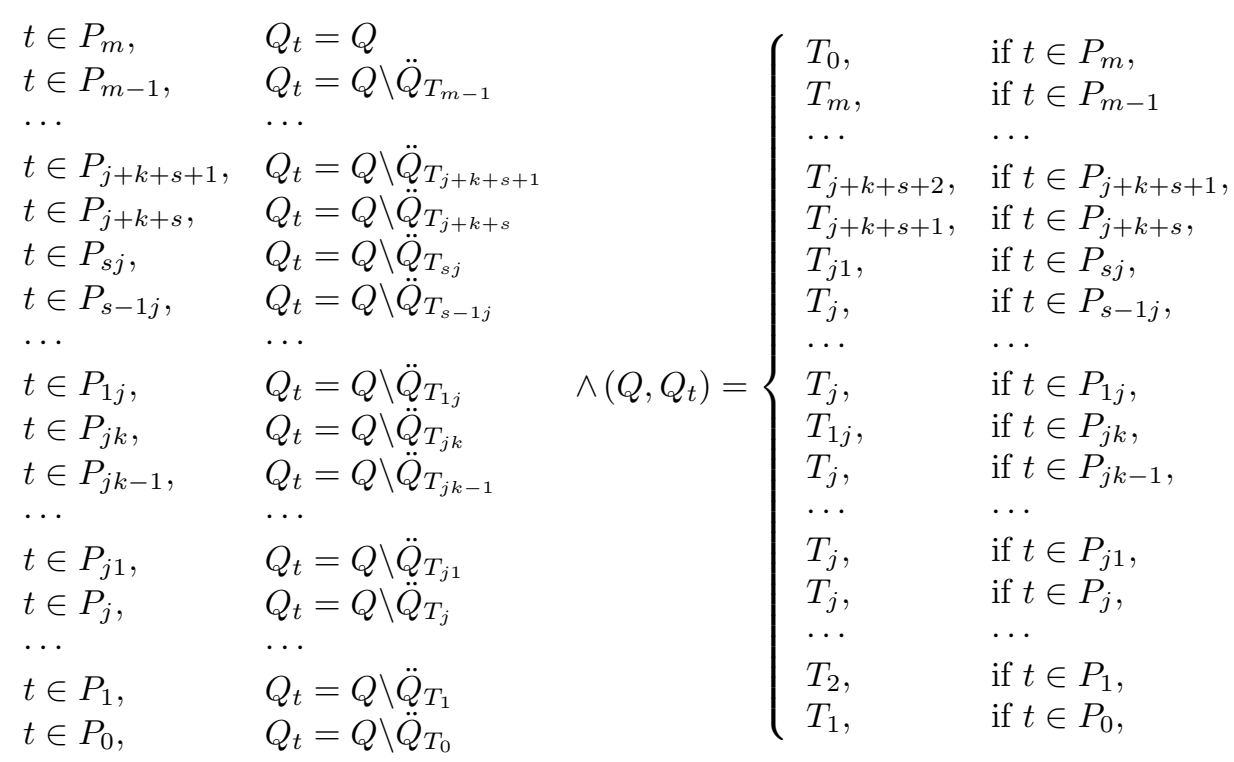

Thus we have obtained that $\wedge\left(Q, Q_{t}\right) \in Q$ for all $t \in T_{m}$. Let

$$
\begin{aligned}
Q^{\wedge} & =\left\{\wedge\left(Q, Q_{t}\right) \mid t \in T_{m}\right\} \\
& =\left\{T_{0}, T_{1}, T_{2}, \ldots, T_{j}, T_{j 1}, \ldots, T_{1 j}, T_{j+k+s+1}, \ldots, T_{m-1}, T_{m}\right\}
\end{aligned}
$$

and $Q^{\prime}$ be the semilattice of unions generated by the set $Q^{\wedge}$.

If $k \geq 2$ or $s \geq 2$, i.e., $T_{j 2} \in Q$ or $T_{2 j} \in Q$ then $T_{j 2} \notin Q^{\prime}$ or $T_{2 j} \notin Q^{\prime}$. So, if $k \geq 2$ or $s \geq 2$, then $Q$ is not $X I$-semilattice of unions.

If $k=s=1$, then $T_{j 1} \cup T_{1 j}=T_{j+2} \in Q^{\prime}$, i.e., $Q^{\prime}=Q$.

Therefore, $Q$ is $X I$-semilattice of unions.

Theorem 2.8. Let $D$ be a $Z$-elementary $X$-semilattice of unions and $Q$ be any $X I$-subsemilattice of the $X$-semilattice of unions $D$. Then for the XI-semilattice $Q$ we have:

a) $Q$ is a finite chain (see. diagram 1 of Fig. 2.4);

b) $Q=\left\{T, T^{\prime}, Z\right\} \cup Q^{\prime}$, where $T$ and $T^{\prime}$ are elements of the semilattice $D$ such that $T \cap T^{\prime}=\emptyset$ and $Q^{\prime}=\left\{T_{1}, T_{2}, \ldots, T_{s}\right\} \subseteq D_{Z} \backslash\{Z\}$ (see. diagram 2 of Fig. 2.4);

c) $Q=Q^{\prime} \cup\left\{T, T^{\prime}, T^{\prime \prime}, Z\right\} \cup Q^{\prime \prime}$, where $T, T^{\prime}, T^{\prime \prime} \in D, T \subset T^{\prime}, T \subset T^{\prime \prime}$, $T^{\prime}, T^{\prime \prime}$ are incomparable elements of $D ; Q^{\prime}=\emptyset$ or $Q^{\prime \prime}=\emptyset$, or $Q^{\prime}, Q^{\prime \prime}$ are subchains of the semilattice $D$ satisfying the conditions $Q^{\prime} \subseteq D_{Z} \backslash\{Z\}$ and $Q^{\prime \prime} \subseteq \ddot{D}_{T} \backslash\{T\}$ (see. diagram 3 of Fig. 2.4). 
Proof. Let $D$ be a $Z$-elementary $X$-semilattice of unions and $Q$ be any $X I$-subsemilattice of the $X$-semilattice of unions $D$.

$\left(a^{\prime}\right)$ If $Z \notin Q$ then by the definition of $Z$-elementary $X$-semilattice of unions it follows that $Q$ is a finite $X$-chain.

Now, let $Z \in Q$ and $T$ be the unique element of the semilattice $Q$ which is covered by the element $Z$; If $T_{1}$ and $T_{2}$ are any incomparable elements of the semilattice $Q$ satisfying the conditions $T_{1} \subset T$ and $T_{2} \subset T$, then by the definition $Z$-elementary $X$-semilattice of unions it follows that $Z=T_{1} \cup T_{2} \subseteq T$. The inclusion $Z \subseteq T$ contradicts the condition $T \subset Z$. So, we have $T_{1}$ and $T_{2}$ are comparable elements of the semilattice $Q$, i.e., $T_{1} \subset T_{2}$ or $T_{2} \subset T_{1}$. Therefore $Q$ is a finite $X$-chain. The statement $\left(a^{\prime}\right)$ is proved.

$\left(b^{\prime}\right)$ Let $T, T^{\prime}$ and $T^{\prime \prime}$ be different elements of the semilattice $Q$ which are covered by the element $Z$ in the semilattice $\mathrm{Q}$. Then

$$
Z=T \cup T^{\prime}=T \cup T^{\prime \prime}=T^{\prime} \cup T^{\prime \prime}
$$

1) If $T \cap T^{\prime}=\emptyset$, then $T=Z \backslash T^{\prime}, T^{\prime}=Z \backslash T$ and

$$
T=Z \backslash T^{\prime}=\left(T^{\prime} \cup T^{\prime \prime}\right) \backslash T^{\prime} \subseteq T^{\prime \prime}, T^{\prime}=Z \backslash T=\left(T \cup T^{\prime \prime}\right) \backslash T \subseteq T^{\prime \prime} .
$$

It follows, that $Z=T \cup T^{\prime} \subseteq T^{\prime \prime} \cup T^{\prime \prime}=T^{\prime \prime}$, i.e., $T^{\prime \prime}=Z$ since $T^{\prime \prime} \subseteq Z$. But the equality $T^{\prime \prime}=Z$ contradict, that $T^{\prime \prime}$ is an element which is covered by the element $Z$ in the semilattice $Q$.

2) Now suppose that the intersection any two different elements which are covered by the element $Z$ in the semilattice $Q$ is not empty.

It is clear that $T \neq \emptyset$ and $T=\bigcup_{t \in T} \wedge\left(Q, Q_{t}\right)$, since $Q$ is $X I$-semilattice of unions. From Lemma 2.3 it follows that $Q$ is $Z$-elementary $X$-semilattice of unions. By the definition of the $Z$-elementary $X$-semilattice of unions $D$ immediately follows that $D \backslash\{Z\}$ is unique generated set of the semilattice $D$. It follows that $T=\wedge\left(Q, Q_{t^{\prime}}\right)$ for some $t^{\prime} \in T$. On the other hand, $t^{\prime} \in T \subset Z=T^{\prime} \cup T^{\prime \prime}$, i.e., $t^{\prime} \in T^{\prime}$ or $t^{\prime} \in T^{\prime \prime}$. If $t^{\prime} \in T^{\prime}$, then we have $T^{\prime} \in Q_{t^{\prime}}$ and $T=\wedge\left(Q, Q_{t^{\prime}}\right) \subset T^{\prime}$. The inclusion $T \subset T^{\prime} \subset Z$ contradicts the assumption that element $T$ is covered by the element $Z$ in the semilattice $Q$. This contradiction shows that number the elements which are covered by the element $Z$ of the $X I$-semilattice $Q$ are less or equal two.

For the elements $T$ and $T^{\prime}$ of the semilattice $Q$ we consider two case.

3) If $T$ and $T^{\prime}$ are minimal elements of the $X$-semilattice unions $Q . T \cap T^{\prime}=\emptyset$ and $Q^{\prime}=Q \backslash\left\{T, T^{\prime}, Z\right\}$, then $Q=\left\{T, T^{\prime}, Z\right\} \cup Q^{\prime}$, where $Q^{\prime}=\left\{T_{1}, T_{2}, \ldots, T_{s}\right\} \subseteq$ $D_{Z} \backslash\{Z\}$ and $Q^{\prime}$ is a chain by definition of $Z$-elementary $X$-semilattice of unions and $Q$. The statement $\left(b^{\prime}\right)$ is proved.

$c^{\prime}$ ) Now suppose that the elements $T^{\prime}$ and $T^{\prime \prime}$ covered by the element $Z$ in the semilattice $Q$ are not minimal elements of the semilattice $Q$, i.e., $T \subset T^{\prime}$ and $T \subset T^{\prime \prime}$ for some $T \in Q$. Then by Lemma 2.7 we have the element $T$ covered by the elements $T^{\prime}$ and $T^{\prime \prime}$ in the semilattice $Q$. It is clear, that the set $\left\{T, T^{\prime}, T^{\prime \prime}, Z\right\}$ is a $X$-subsemilattice of the semilattice $Q$. 
Further, let $Q^{\prime}=\left\{Z^{\prime} \in Q \mid Z \subset Z^{\prime}\right\}$ and $Q^{\prime \prime}=Q \backslash\left(Q^{\prime} \cup\left\{T, T^{\prime}, T^{\prime \prime}, Z\right\}\right)$. Then we have

$$
Q=Q^{\prime} \cup\left\{T, T^{\prime}, T^{\prime \prime}, Z\right\} \cup Q^{\prime \prime} .
$$

It is clear that $Q^{\prime} \subseteq D_{Z} \backslash\{Z\}$ and is a subchain of the chain $D_{Z}$.

Now, let $Z^{\prime \prime}$ be any element of the set $Q^{\prime \prime}$. Then $Z^{\prime \prime} \in Q, Z^{\prime \prime} \notin Q^{\prime} \cup\left\{T, T^{\prime}, T^{\prime \prime}, Z\right\}$ and $Z^{\prime \prime} \subset T^{\prime}$ or $Z^{\prime \prime} \subset T^{\prime \prime}$ since $T^{\prime}$ and $T^{\prime \prime}$ are maximal elements of the set $Q \backslash\left(Q^{\prime} \cup\{Z\}\right)$. If $Z^{\prime \prime}$ and $T$ are incomparable elements of the semilattice $Q$ then $Z=T \cup Z^{\prime \prime} \subseteq T^{\prime}$ by the definition of $Z$-elementary $X$-semilattice unions and by the conditions $T \subset T^{\prime}$ and $Z^{\prime \prime} \subset T^{\prime}$. But the inclusion $Z \subseteq T^{\prime}$ contradicts the conditions $T^{\prime} \subset Z$. So, $Z^{\prime \prime}$ and $T$ are comparable elements of the semilattice $Q$. From this follows that $Z^{\prime \prime} \subset T$.

In the case $Z^{\prime \prime} \subset T^{\prime \prime}$ we can similarly prove that $Z^{\prime \prime} \subset T$.

Further let $Z_{1}^{\prime \prime}$ and $Z_{2}^{\prime \prime}$ are any incomparable elements of the set $Q^{\prime \prime}$ satisfying the conditions $Z_{1}^{\prime \prime} \subset T$ and $Z_{2}^{\prime \prime} \subset T$. Then by the definition $Z$-elementary $X$-semilattice of unions it follows that $Z=Z_{1}^{\prime \prime} \cup Z_{2}^{\prime \prime} \subseteq T$. The inclusion $Z \subseteq T$ contradicts the condition $T \subset Z$. So, we have $Z_{1}^{\prime \prime}$ and $Z_{2}^{\prime \prime}$ are comparable elements of the set $Q^{\prime \prime}$, i.e., $Z_{1}^{\prime \prime} \subset Z_{2}^{\prime \prime}$ or $Z_{2}^{\prime \prime} \subset Z_{1}^{\prime \prime}$. Therefore $Q^{\prime \prime}$ is a finite $X$-chain for which $\ddot{Q} \subseteq \ddot{D}_{T} \backslash\{T\}$. The statement $\left(c^{\prime}\right)$ is proved.

Definition 2.9. Let $C(D)$ denote the set all chains of the $Z$-elementary $X$-semilattice unions $D . N(D)=\{|C| \mid C \in C(D)\}, h(D)$ be the largest natural number of the set $N(D)$,

$$
\begin{aligned}
C_{k}(D) & =\{C \in C(D)|| C \mid=k\} \quad(1 \leq k \leq h(D)), \\
I_{C_{k}(D)}^{*} & =\left\{\alpha \in B_{X}(D) \mid \alpha \circ \alpha=\alpha, V(D, \alpha) \subseteq C_{k}(D)\right\}, \\
I_{C(D)} & =\left\{\alpha \in B_{X}(D) \mid \alpha \circ \alpha=\alpha, V(D, \alpha) \subseteq C(D)\right\} .
\end{aligned}
$$

It is easy to see, that: $C(D)=C_{1}(D) \cup C_{2}(D) \cup \cdots \cup C_{h(D)}(D)$.

Theorem 2.10. Let $Q=\left\{T_{0}, T_{1}, \ldots, T_{m}\right\}$ be a subsemilattice of the semilattice $D$ such that $T_{0} \subset T_{1} \subset \cdots \subset T_{m}$ (see Fig. 2.5). Then a binary relation $\alpha$ of the semigroup $B_{X}(D)$ that has a quasinormal representation of the form $\alpha=$ $\bigcup_{i=0}^{m}\left(Y_{i}^{\alpha} \times T_{i}\right)$ is a right unit of the semigroup $B_{X}(Q)$ iff $Q=V(D, \alpha)$ and $Y_{1}^{\alpha} \cup$ $Y_{2}^{\alpha} \cup \cdots \cup Y_{p}^{\alpha} \supseteq T_{p}, Y_{q}^{\alpha} \cap T_{q} \neq \emptyset$ for any $p=1,2, \ldots, m-1$ and $q=1,2, \ldots, m$.

Proof. Let $Q=\left\{T_{0}, T_{1}, \ldots, T_{m}\right\}$ be a subsemilattice of the semilattice $D$ such that $T_{0} \subset T_{1} \subset \cdots \subset T_{m}$. Then the given Theorem immediately follows from the Theorem 1.6 and Corollary 3 of [5]. (see, also, Corollary 13.1.2 of [1]) .

Theorem 2.11. Let $Q=\left\{T_{0}, T_{1}, \ldots, T_{m}\right\}$ be a subsemilattice of the semilattice $D$ such that $T_{0} \subset T_{1} \subset \cdots \subset T_{m}$. If $E_{X}^{(r)}(Q)$ is the set of all right units of the semigroup $B_{X}(Q)$, then

$$
\begin{aligned}
E_{X}^{(r)}(Q) & =\left(2^{\left|T_{1} \backslash T_{0}\right|}-1\right)\left(3^{\left|T_{2} \backslash T_{1}\right|}-2^{\left|T_{2} \backslash T_{1}\right|}\right) \cdots \\
& \left((m+1)^{\left|T_{m} \backslash T_{m-1}\right|}-m^{\left|T_{m} \backslash T_{m-1}\right|}\right)(m+1)^{\left|X \backslash T_{m}\right|}
\end{aligned}
$$

(see, Theorem 6.5 of [2] or Corollary 13.1.5 of [1]). 
Definition 2.12. Let $\mu=\left\{\left(T, T^{\prime}\right) \mid T, T^{\prime} \in D, T \cap T^{\prime}=\emptyset\right\} \neq \emptyset, Q\left(T, T^{\prime}, Q^{\prime}\right)=$ $\left\{T, T^{\prime}, Z\right\} \cup Q^{\prime}$ where $\left(T, T^{\prime}\right) \in \mu, Q^{\prime} \subseteq D_{Z} \backslash\{Z\}$,

$$
C^{\prime}(D)=\left\{Q\left(T, T^{\prime}, Q^{\prime}\right) \mid\left(T, T^{\prime}\right) \in \mu, Q^{\prime} \subseteq D_{Z} \backslash\{Z\}\right\}
$$

and

$$
\begin{aligned}
& C_{s}^{\prime}(D)=\left\{Q\left(T, T^{\prime}, Q^{\prime}\right) \in C^{\prime}(D)|| Q^{\prime} \mid=s\right\} \quad\left(0 \leq s \leq 2^{\left|D_{z} \backslash\{Z\}\right|}\right), \\
& I_{C_{s}^{\prime}(D)}^{*}=\left\{\alpha \in B_{X}(D) \mid \alpha \circ \alpha=\alpha, V(D, \alpha) \subseteq C_{s}^{\prime}(D)\right\}, \\
& I_{C^{\prime}(D)}^{*}=\left\{\alpha \in B_{X}(D) \mid \alpha \circ \alpha=\alpha, V(D, \alpha) \subseteq C^{\prime}(D)\right\} .
\end{aligned}
$$

It is easy to see, that $C^{\prime}(D)=C_{0}^{\prime}(D) \cup C_{1}^{\prime}(D) \cup \cdots \cup C_{2^{\left|D_{Z} \backslash\{Z\}\right|}}(D)$.

Theorem 2.13. Let $Q=\left\{T_{1}, T_{2}, \ldots, T_{m}\right\}(m \geq 3)$ be a subsemilattice of the semilattice $D$ such that $T_{1}, T_{2} \notin\{\emptyset\}, T_{1} \cap T_{2}=\emptyset, T_{1} \cup T_{2}=T_{3}, T_{3} \subset T_{4} \subset \cdots \subset T_{m}$. Then the semigroup $B_{X}(Q)$ has right unit iff $T_{1} \cap T_{2}=\emptyset$ (see [6], Theorem 1).

Theorem 2.14. Let $Q=\left\{T_{1}, T_{2}, \ldots, T_{m}\right\}(m \geq 3)$ be a subsemilattice of the semilattice $D$ such that $T_{1}, T_{2} \notin\{\emptyset\}, T_{1} \cap T_{2}=\emptyset, T_{1} \cup T_{2}=T_{3}, T_{3} \subset T_{4} \subset \cdots \subset T_{m}$, (see Fig. 2.6). Then a binary relation $\alpha$ of the semigroup $B_{X}(Q)$ that has a quasinormal representation of the form $\alpha=\bigcup_{i=0}^{m}\left(Y_{i}^{\alpha} \times T_{i}\right)$ is a right unit of the semigroup $B_{X}(Q)$ iff $Q=V(D, \alpha)$ and $Y_{1}^{\alpha} \supseteq T_{1}, Y_{2}^{\alpha} \supseteq T_{2}, Y_{1}^{\alpha} \cup Y_{2}^{\alpha} \cup \cdots \cup Y_{k}^{\alpha} \supseteq T_{k}$ and $Y_{q}^{\alpha} \cap T_{q} \neq \emptyset$ for any $k=4,5, \ldots, m-1$ and $q=4,5, \ldots, m-1$ (see Corollary 13.2.3 of $[1])$.

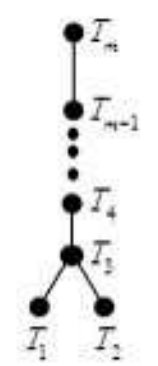

Fig. 2.6

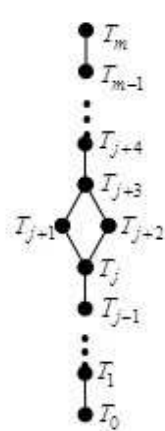

Fig. 2.7

Theorem 2.15. Let $Q=\left\{T_{1}, T_{2}, \ldots, T_{m}\right\}$ ( $\left.m \geq 3\right)$ be a subsemilattice of the semilattice $D$ such that $T_{1}, T_{2} \notin\{\emptyset\}, T_{1} \cap T_{2}=\emptyset, T_{1} \cup T_{2}=T_{3}, T_{3} \subset T_{4} \subset \cdots \subset T_{m}$. If $E_{X}^{(r)}(Q)$ is the set of all right units of the semigroup $B_{X}(Q)$, then

$$
\begin{gathered}
E_{X}^{(r)}(Q)=\left(4^{\left|T_{4} \backslash T_{3}\right|}-3^{\left|T_{4} \backslash T_{3}\right|}\right)\left(5^{\left|T_{5} \backslash T_{4}\right|}-4^{\left|T_{5} \backslash T_{4}\right|}\right) \cdots \\
\left(m^{\left|T_{m} \backslash T_{m-1}\right|}-(m-1)^{\left|T_{m} \backslash T_{m-1}\right|}\right) m^{\left|X \backslash T_{m}\right|}
\end{gathered}
$$

(see Corollary 13.2.1 of [1]). 


\section{Definition 2.16. Let}

$$
\begin{gathered}
v=\left\{\left(T, T^{\prime}, T^{\prime \prime}\right) \mid T, T^{\prime}, T^{\prime \prime} \in D, T \subset T^{\prime}, T \subset T^{\prime \prime}, T^{\prime} \backslash T^{\prime \prime} \neq \emptyset, T^{\prime \prime} \backslash T^{\prime} \neq \emptyset\right\} \neq \emptyset, \\
Q\left(T, T^{\prime}, T^{\prime \prime}, Q^{\prime}, Q^{\prime \prime}\right)=Q^{\prime} \cup\left\{T, T^{\prime}, T^{\prime \prime}, Z\right\} \cup Q^{\prime \prime}
\end{gathered}
$$

and $C^{\prime \prime}(D)$ be set of all $Q\left(T, T^{\prime}, T^{\prime \prime}, Q^{\prime}, Q^{\prime \prime}\right)$, where $\left(T, T^{\prime}, T^{\prime \prime}\right) \in v, Q^{\prime}=\emptyset$ or $Q^{\prime \prime}=\emptyset$, or $Q^{\prime}, Q^{\prime \prime}$ are subchains of the semilattice $D$ satisfying the conditions $Q^{\prime} \subseteq D_{Z} \backslash\{Z\}$ and $\ddot{Q} \subseteq \ddot{D}_{T} \backslash\{T\}$.

Further, let

$$
\begin{aligned}
C_{s k}^{\prime \prime}\left(T, T^{\prime}, T^{\prime \prime}, D\right) & =\left\{Q\left(T, T^{\prime}, T^{\prime \prime}, Q^{\prime}, Q^{\prime \prime}\right)|| Q^{\prime}|=s,| Q^{\prime \prime} \mid=k\right\} \quad\left(\left(T, T^{\prime}, T^{\prime \prime}\right) \in v\right), \\
I_{C_{s k}^{\prime \prime}\left(T, T^{\prime}, T^{\prime \prime}, D\right)}^{*} & =\left\{\alpha \in B_{X}(D) \mid \alpha \circ \alpha=\alpha, V(D, \alpha) \subseteq C_{s k}^{\prime \prime}\left(T, T^{\prime}, T^{\prime \prime}, D\right)\right\}, \\
I_{C^{\prime \prime}(D)} & =\left\{\alpha \in B_{X}(D) \mid \alpha \circ \alpha=\alpha, V(D, \alpha) \subseteq C^{\prime \prime}(D)\right\},
\end{aligned}
$$

where $0 \leq s \leq 2^{\left|D_{Z} \backslash\{Z\}\right|}$ and $0 \leq k \leq 2^{\left|\ddot{D}_{Z} \backslash\{Z\}\right|}$.

It is easy to see, that $C^{\prime \prime}(D)=\bigcup_{\left(T, T^{\prime}, T^{\prime \prime}\right) \in v} C_{s k}^{\prime \prime}\left(T, T^{\prime}, T^{\prime \prime}, D\right)$.

Theorem 2.17. Let $Q=\left\{T_{0}, T_{1}, \ldots, T_{m}\right\}(m \geq 3)$ be a semilattice and $j$ be a fixed natural number such that $0 \leq j \leq m-3$ and

$$
\begin{aligned}
T_{0} & \subset T_{1} \subset \cdots \subset T_{j} \subset T_{j+1} \subset T_{j+3} \subset \cdots \subset T_{m}, \\
T_{0} & \subset T_{1} \subset \cdots \subset T_{j} \subset T_{j+2} \subset T_{j+3} \subset \cdots \subset T_{m}, \\
T_{j+1} \backslash T_{j+2} & \neq \emptyset, T_{j+2} \backslash T_{j+1} \neq \emptyset, T_{j+1} \cup T_{j+2}=T_{j+3}
\end{aligned}
$$

(see Fig. 2.7). A binary representation $\alpha$ of the semigroup $B_{X}(Q)$, which has a quasinormal representation of the form $\alpha=\bigcup_{i=0}^{m}\left(Y_{i}^{\alpha} \times T_{i}\right)$ such that $Q=V(D, \alpha)$, is an idempotent element of the semigroup $B_{X}(D)$ iff

$$
\begin{gathered}
Y_{0}^{\alpha} \cup Y_{1}^{\alpha} \cup \cdots \cup Y_{j}^{\alpha} \supseteq T_{j+1} \cap T_{j+2}, \\
Y_{0}^{\alpha} \cup Y_{1}^{\alpha} \cup \cdots \cup Y_{j}^{\alpha} \cup Y_{j+2}^{\alpha} \supseteq T_{j+2}, \\
Y_{0}^{\alpha} \cup Y_{1}^{\alpha} \cup \cdots \cup Y_{p}^{\alpha} \supseteq T_{p}, Y_{p}^{\alpha} \cap T_{p} \neq \emptyset
\end{gathered}
$$

for any $p=0,1,2, \ldots, m-1, q=1,2, \ldots, m(p \neq j+2, q \neq j+3)$ (see Corollary 13.3.1 of [1]).

Theorem 2.18. Let $Q=\left\{T_{0}, T_{1}, \ldots, T_{j}, \ldots, T_{m}\right\}(m \geq 3)$ be a semilattice and $j$ be a fixed natural number such that $0 \leq j \leq m-3$ and

$$
\begin{gathered}
T_{0} \subset T_{1} \subset \cdots \subset T_{j} \subset T_{j+1} \subset T_{j+3} \subset \cdots \subset T_{m}, \\
T_{0} \subset T_{1} \subset \cdots \subset T_{j} \subset T_{j+2} \subset T_{j+3} \subset \cdots \subset T_{m}, \\
T_{j+1} \backslash T_{j+2} \neq \emptyset, T_{j+2} \backslash T_{j+1} \neq \emptyset, T_{j+1} \cup T_{j+2}=T_{j+3} .
\end{gathered}
$$

If $E_{X}^{(r)}(Q)$ is the set of all right units of the semigroup $B_{X}(Q)$, then the following statements are true:

a) $\left|E_{X}^{(r)}(Q)\right|=\left(2^{\left|T_{1} \backslash T_{2}\right|}-1\right)\left(2^{\left|T_{2} \backslash T_{1}\right|}-1\right)\left(5^{\left|T_{4} \backslash T_{3}\right|}-4^{\left|T_{4} \backslash T_{3}\right|}\right)$

$$
\begin{aligned}
& \cdots\left((m+1)^{\left|T_{m} \backslash T_{m-1}\right|}-m^{\left|T_{m} \backslash T_{m-1}\right|}\right)(m+1)^{\left|X \backslash T_{m}\right|}, \\
\text { If } j=0 & \left(\text { i.e. }, T_{j}=T_{0}\right) ;
\end{aligned}
$$


b) $\left|E_{X}^{(r)}(Q)\right|=\left(2^{\left|T_{1} \backslash T_{0}\right|}-1\right)\left((j+1)^{\left|T_{i} \backslash T_{i-1}\right|}-j^{\left|T_{i} \backslash T_{i-1}\right|}\right)$

$$
\begin{aligned}
& (j+1)^{\left|T_{i+1} \cap T_{i+2} \backslash T_{i}\right|}\left((j+2)^{\left|T_{j+1} \backslash T_{j+2}\right|}-(j+1)^{\left|T_{j+1} \backslash T_{j+2}\right|}\right) \\
& \left((j+2)^{\left|T_{j+2} \backslash T_{j+1}\right|}-(j+1)^{\left|T_{j+2} \backslash T_{j+1}\right|}\right) \\
& \left((j+5)^{\left|T_{j+4} \backslash T_{j+3}\right|}-(j+4)^{\left|T_{j+4} \backslash T_{j+3}\right|}\right) \\
& \cdots\left((m+1)^{\left|T_{m} \backslash T_{m-1}\right|}-m^{\left|T_{m} \backslash T_{m-1}\right|}\right)(m+1)^{\left|X \backslash T_{m}\right|}, \\
\text { if } 1 \leq & \left.j \leq m-3\left(T_{j} \neq T_{0}\right) \text { (see Corollary } 13.3 .3 \text { of }[1]\right) .
\end{aligned}
$$

Theorem 2.19. If $D$ is $Z$-elementary $X$-semilattice of unions, then the following equalities are true:

$$
\begin{gathered}
\left|I_{C(D)}\right|=\left|I_{C_{1}(D)}^{*}\right|+\left|I_{C_{2}(D)}^{*}\right|+\cdots+\left|I_{C_{k}(D)}^{*}\right| \\
\left|I_{C^{\prime}(D)}\right|=\left|I_{C_{0}^{\prime}(D)}^{*}\right|+\left|I_{C_{1}^{\prime}(D)}^{*}\right|+\cdots+\left|I_{C_{2}^{\prime}\left|D E_{Z} \backslash\{Z\}\right|}^{*}(D)\right| \\
\left|I_{C^{\prime \prime}(D)}\right|=\sum_{\left(T, T^{\prime}, T^{\prime \prime}\right) \in v}\left|I_{C_{s k}^{\prime}\left(T, T^{\prime}, T^{\prime \prime}, D\right)}^{*}\right|
\end{gathered}
$$

Proof. The given Theorem immediately follows from the Theorem 1.8.

Theorem 2.20. Let $D$ be $Z$-elementary $X$-semilattice of unions and $\alpha \in B_{X}(D)$. Binary relation $\alpha$ is an idempotent relation of the semigroup $B_{X}(D)$ iff binary relation $\alpha$ satisfies only one condition of the following conditions:

a) $\alpha=(X \times T)$, where $T \in D$;

b) $\alpha=\left(Y_{0}^{\alpha} \times T_{0}\right) \cup\left(Y_{1}^{\alpha} \times T_{1}\right) \cup \cdots \cup\left(Y_{k}^{\alpha} \times T_{k}\right)$, where $T_{0}, T_{1}, \cdots, T_{k} \in D$, $T_{0} \subset T_{1} \subset \cdots \subset T_{k}, 2 \leq k \leq h(D), Y_{1}^{\alpha}, \ldots, Y_{k-1}^{\alpha}, Y_{k}^{\alpha} \notin\{\emptyset\}$ and satisfies the conditions: $Y_{1}^{\alpha} \cup Y_{2}^{\alpha} \cup \cdots \cup Y_{p}^{\alpha} \supseteq T_{p}, Y_{q}^{\alpha} \cap T_{q} \neq \emptyset$ for any $p=$ $0,1, \ldots, k-1$ and $q=1,2, \ldots, k$;

c) $\alpha=\left(Y_{T}^{\alpha} \times T\right) \cup\left(Y_{T^{\prime}}^{\alpha} \times T^{\prime}\right) \cup\left(Y_{Z}^{\alpha} \times Z\right)$, where $T, T^{\prime} \in D, T_{1} \cap T_{2}=\emptyset$, $Y_{T}^{\alpha}, Y_{T^{\prime}}^{\alpha} \notin\{\emptyset\}$ and satisfies the conditions: $Y_{T}^{\alpha} \supseteq T, Y_{T^{\prime}}^{\alpha} \supseteq T^{\prime}$;

d) $\alpha=\left(Y_{1}^{\alpha} \times T_{1}\right) \cup\left(Y_{2}^{\alpha} \times T_{2}\right) \cup \cdots \cup\left(Y_{s}^{\alpha} \times T_{s}\right)$, where $T_{1}, T_{2}, \ldots, T_{s} \in D$, $T_{1}=T, T_{2}=T^{\prime}, T_{3}=Z, 4 \leq s \leq 2^{\left|D_{Z} \backslash\{Z\}\right|}, T_{1} \cap T_{2}=\emptyset, Y_{1}^{\alpha}, Y_{2}^{\alpha}$, $Y_{4}^{\alpha}, Y_{5}^{\alpha}, \ldots, Y_{s}^{\alpha} \notin\{\emptyset\}$ and satisfies the conditions: $Y_{1}^{\alpha} \supseteq T_{1}, Y_{2}^{\alpha} \supseteq T_{2}$, $Y_{1}^{\alpha} \cup Y_{2}^{\alpha} \cup Y_{3}^{\alpha} \cup \cdots \cup Y_{p}^{\alpha} \supseteq T_{p}$ and $Y_{q}^{\alpha} \cap T_{q} \neq \emptyset$ for any $p=4,5, \ldots, s-1$ and $q=4,5, \ldots, s$;

e) $\alpha=\left(Y_{0}^{\alpha} \times T_{0}\right) \cup\left(Y_{1}^{\alpha} \times T_{1}\right) \cup \cdots \cup\left(Y_{j-1}^{\alpha} \times T_{j-1}\right) \cup\left(Y_{j}^{\alpha} \times T_{j}\right) \cup\left(Y_{j+1}^{\alpha} \times T_{j+1}\right)$ $\cup\left(Y_{j+2}^{\alpha} \times T_{j+2}\right) \cup\left(Y_{j+3}^{\alpha} \times T_{j+3}\right) \cup \cdots \cup\left(Y_{m-1}^{\alpha} \times T_{m-1}\right) \cup\left(Y_{m}^{\alpha} \times T_{m}\right)$, where $T_{0}, \ldots, T_{j-1}, T, T^{\prime}, T^{\prime \prime}, Z, T_{j+3}, \ldots, T_{m-1}, T_{m} \in D, T_{j}=T, T_{j+1}=T^{\prime}$, $T_{j+2}=T^{\prime \prime}, T_{j+3}=Z, Y_{0}^{\alpha}, Y_{1}^{\alpha}, \ldots, Y_{j-1}^{\alpha}, Y_{j}^{\alpha}, Y_{j+1}^{\alpha}, Y_{j+2}^{\alpha}, Y_{j+4}^{\alpha}, \ldots, Y_{m}^{\alpha} \notin$ $\{\emptyset\}$ and satisfies the conditions:

$$
\begin{gathered}
Y_{0}^{\alpha} \cup Y_{1}^{\alpha} \cup \cdots \cup Y_{j}^{\alpha} \supseteq T_{j+1} \cap T_{j+2}, \\
Y_{0}^{\alpha} \cup Y_{1}^{\alpha} \cup \cdots \cup Y_{j}^{\alpha} \cup Y_{j+2}^{\alpha} \supseteq T_{j+2}, \\
Y_{0}^{\alpha} \cup Y_{1}^{\alpha} \cup \cdots \cup Y_{p}^{\alpha} \supseteq T_{p}^{\alpha}, Y_{q}^{\alpha} \cap T_{q} \neq \emptyset
\end{gathered}
$$


for any $p=0,1, \ldots, m-1, q=1,2, \ldots, m(p \neq j+2, q \neq j+3)$ (see Corollary 13.3.1 of [1]).

Proof. The given Theorem immediately follows from the Theorem 2.10, 2.14 and 2.17 .

Theorem 2.21. Let $D$ and $I_{D}$ be any $Z$-elementary $X$-semilattice of unions and all idempotent elements of the $Z$-elementary $X$-semilattice of unions respectively. Then the following conditions are true.
a) $\left|I_{D}\right|=\left|I_{C(D)}\right|$, if $\mu=\emptyset$ and $\nu=\emptyset$;
b) $\left|I_{D}\right|=\left|I_{C(D)}\right|+\left|I_{C^{\prime}(D)}\right|$ if $\mu \neq \emptyset$ and $\nu=\emptyset$;
c) $\left|I_{D}\right|=\left|I_{C(D)}\right|+\left|I_{C^{\prime}(D)}\right|$ if $\mu=\emptyset$ and $\nu \neq \emptyset$;
d) $\left|I_{D}\right|=\left|I_{C(D)}\right|+\left|I_{C^{\prime}(D)}\right|+\left|I_{C^{\prime}(D)}\right|$ if $\mu \neq \emptyset$ and $\nu \neq \emptyset$.

Proof. The given Theorem immediately follows from the Theorem 2.19.

Theorem 2.22. If $D$ is any $Z$-elementary $X$-semilattice of unions, then for any idempotent binary relation $\varepsilon$ from the semigroup $B_{X}(D)$ the order of maximal subgroup $G_{X}(D, \varepsilon)$ is not greater than two.

Proof. Let $D$ be any $Z$-elementary $X$-semilattice of unions and $\varepsilon \circ \varepsilon=\varepsilon$. As is known (see [1]) the group $G_{X}(D, \varepsilon)$ is anti-isomorphic to the group of all complete automorphisms of the semilattice $V(D, \varepsilon)$. In this case the number of all complete automorphisms of the semilattice $V(D, \varepsilon)$ is not greater than two. Therefore the order of maximal subgroup $G_{X}(D, \varepsilon)$ is not greater than two.

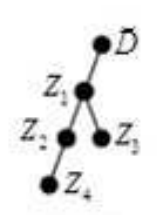

Fig. 2.8

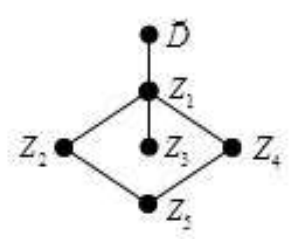

Fig. 2.9

Example 2. Let $D=\left\{Z_{4}, Z_{3}, Z_{2}, Z_{1}, \breve{D}\right\}$ be $Z_{1}$-elementary $X$-semilattice of unions satisfying the conditions

$$
\begin{aligned}
& Z_{3} \subset Z_{2} \subset Z_{1} \subset \breve{D}, Z_{3} \subset Z_{1} \subset \breve{D}, Z_{4} \backslash Z_{3} \neq \emptyset \\
& Z_{3} \backslash Z_{4} \neq \emptyset, Z_{3} \backslash Z_{2} \neq \emptyset, Z_{2} \backslash Z_{3} \neq \emptyset \\
& Z_{4} \cup Z_{3}=Z_{1}, Z_{3} \cup Z_{2}=Z_{1} .
\end{aligned}
$$

The semilattice satisfying the conditions (2.1) is shown in Fig. 2.8.

Let $C(D)=\left\{P_{0}, P_{1}, P_{2}, P_{3}, P_{4}\right\}$ be a family sets, where $P_{0}, P_{1}, P_{2}, P_{3}, P_{4}$ are pairwise disjoint subsets of the set $X$ and

$$
\varphi=\left(\begin{array}{ccccc}
\breve{D} & Z_{1} & Z_{2}, Z_{3} & Z_{4} \\
P_{0} & P_{1} & P_{2} & P_{3} & P_{4}
\end{array}\right)
$$


is a mapping of the semilattice $D$ onto the family sets $C(D)$. Then for the formal equalities of the semilattice $D$ we have a form:

$$
\begin{aligned}
& \breve{D}=P_{0} \cup P_{1} \cup P_{2} \cup P_{3} \cup P_{4} \\
& Z_{1}=P_{0} \cup P_{2} \cup P_{3} \cup P_{4} \\
& Z_{2}=P_{0} \cup P_{3} \cup P_{4} \\
& Z_{3}=P_{0} \cup P_{2} \cup P_{4} \\
& Z_{4}=P_{0} \cup P_{3} .
\end{aligned}
$$

Here the elements $P_{1}, P_{2}, P_{3}, P_{4}$ are basic sources; the elements $P_{0}$ are sources of completeness of the $Z_{1}$-elementary $X$-semilattice of unions $D$.

Further, we have $Z_{4} \cap Z_{3}=\left(P_{0} \cup P_{3}\right) \cap\left(P_{0} \cup P_{2} \cup P_{4}\right)=P_{0}$.

(1) If $Z_{4} \cap Z_{3} \neq \emptyset\left(P_{0} \neq \emptyset\right)$, then $h(D)=4, \mu=\nu=\emptyset$

$$
\begin{aligned}
& C_{1}(D)=\left\{\left\{Z_{4}\right\},\left\{Z_{3}\right\},\left\{Z_{2}\right\},\left\{Z_{1}\right\},\{\breve{D}\}\right\} \\
& C_{2}(D)=\left\{\begin{array}{l}
\left\{Z_{4}, Z_{2}\right\},\left\{Z_{4}, Z_{1}\right\},\left\{Z_{4}, \breve{D}\right\},\left\{Z_{3}, Z_{1}\right\},\left\{Z_{3}, \breve{D}\right\},\left\{Z_{2}, Z_{1}\right\}, \\
\left\{Z_{2}, \breve{D}\right\}\left\{Z_{1}, \breve{D}\right\}
\end{array}\right\} \\
& C_{3}(D)=\left\{\left\{Z_{2}, Z_{1}, \breve{D}\right\},\left\{Z_{4}, Z_{1}, \breve{D}\right\},\left\{Z_{4}, Z_{2}, \breve{D}\right\},\left\{Z_{4}, Z_{2}, Z_{1}\right\},\left\{Z_{3}, Z_{1}, \breve{D}\right\}\right\} \\
& C_{4}(D)=\left\{\left\{Z_{4}, Z_{2}, Z_{1}, \breve{D}\right\}\right\} \\
& C(D)=C_{1}(D) \cup C_{2}(D) \cup C_{3}(D) \cup C_{4}(D)
\end{aligned}
$$

and $\left|I_{C(D)}\right|=\left|I_{C_{1}(D)}\right|+\left|I_{C_{2}(D)}\right|+\left|I_{C_{3}(D)}\right|+\left|I_{C_{4}(D)}\right|$, where

$$
\begin{aligned}
& \left|I_{C_{1}(D)}^{*}\right|=5 ; \\
& \mid I_{C_{2}(D)}^{*}=\left(2^{\left|Z_{2} \backslash Z_{4}\right|}-1\right) 2^{\left|X \backslash Z_{2}\right|}+\left(2^{\left|Z_{1} \backslash Z_{4}\right|}+2^{\left|Z_{1} \backslash Z_{3}\right|}+2^{\left|Z_{1} \backslash Z_{2}\right|}-3\right) 2^{\left|X \backslash Z_{1}\right|} \\
& +\left(2^{\left|\breve{D} \backslash Z_{4}\right|}+2^{\left|\breve{D} \backslash Z_{3}\right|}+2^{\left|\breve{D} \backslash Z_{2}\right|}+2^{\left|\breve{D} \backslash Z_{1}\right|}-4\right) 2^{|X \backslash \breve{D}|} ; \\
& \left|I_{C_{3}(D)}^{*}\right|=\left(2^{\left|Z_{1} \backslash Z_{2}\right|}-1\right)\left(3^{\left|\breve{D} \backslash Z_{1}\right|}-2^{\left|\breve{D} \backslash Z_{1}\right|}\right) 3^{|X \backslash \breve{D}|} \\
& +\left(2^{\left|Z_{1} \backslash Z_{4}\right|}-1\right)\left(3^{\left|\breve{D} \backslash Z_{1}\right|}-2^{\left|\breve{D} \backslash Z_{1}\right|}\right) 3^{|X \backslash \breve{D}|}+\left(2^{\left|Z_{2} \backslash Z_{4}\right|}-1\right)\left(3^{\left|\breve{D} \backslash Z_{2}\right|}-2^{\left|\breve{D} \backslash Z_{2}\right|}\right) 3^{|X \backslash \breve{D}|} \\
& +\left(2^{\left|Z_{2} \backslash Z_{4}\right|}-1\right)\left(3^{\left|Z_{1} \backslash Z_{2}\right|}-2^{\left|Z_{1} \backslash Z_{2}\right|}\right) 3^{\left|X \backslash Z_{1}\right|}+\left(2^{\left|Z_{1} \backslash Z_{3}\right|}-1\right)\left(3^{\left|\breve{D} \backslash Z_{1}\right|}-2^{\left|\breve{D} \backslash Z_{1}\right|}\right) 3^{|X \backslash \breve{D}|} \\
& \left|I_{C_{4}(D)}^{*}\right|=\left(2^{\left|Z_{2} \backslash Z_{4}\right|}-1\right)\left(3^{\left|Z_{1} \backslash Z_{2}\right|}-2^{\left|Z_{1} \backslash Z_{2}\right|}\right)\left(3^{\left|\breve{D} \backslash Z_{1}\right|}-2^{\left|\breve{D} \backslash Z_{1}\right|}\right) 4^{|X \backslash \breve{D}|}
\end{aligned}
$$

(see Theorem 2.4).

If $X=\{1,2,3,4,5\}, D=\{\{3,5\},\{2,4,5\},\{3,4,5\},\{2,3,4,5\},\{1,2,3,4,5\}\}$ then $\left|I_{C_{1}(D)}^{*}\right|=5,\left|I_{C_{2}(D)}^{*}\right|=28,\left|I_{C_{3}(D)}^{*}\right|=13,\left|I_{C_{4}(D)}^{*}\right|=1,\left|I_{C(D)}\right|=47$.

(2) If $Z_{4} \cap Z_{3}=\emptyset\left(P_{0}=\emptyset\right)$, then $\mu=\left\{\left\{Z_{4}, Z_{3}\right\}\right\}, \nu=\emptyset, h(D)=4, s=0,1$ and

$$
\begin{aligned}
& C_{1}(D)=\left\{\left\{Z_{4},\right\},\left\{Z_{3}\right\},\left\{Z_{2}\right\},\left\{Z_{1}\right\},\{\breve{D}\}\right\} \\
& C_{2}(D)=\left\{\begin{array}{l}
\left\{Z_{4}, Z_{2}\right\},\left\{Z_{4}, Z_{1}\right\},\left\{Z_{4}, \breve{D}\right\},\left\{Z_{3}, Z_{1}\right\},\left\{Z_{3}, \breve{D}\right\},\left\{Z_{2}, Z_{1}\right\}, \\
\left\{Z_{2}, \breve{D}\right\}\left\{Z_{1}, \breve{D}\right\}
\end{array}\right\},
\end{aligned}
$$




$$
\begin{aligned}
& C_{3}(D)=\left\{\left\{Z_{2}, Z_{1}, \breve{D}\right\},\left\{Z_{4}, Z_{1}, \breve{D}\right\},\left\{Z_{4}, Z_{2}, \breve{D}\right\},\left\{Z_{4}, Z_{2}, Z_{1}\right\},\left\{Z_{3}, Z_{1}, \breve{D}\right\}\right\} \\
& C_{4}(D)=\left\{\left\{Z_{4}, Z_{2}, Z_{1}, \breve{D}\right\}\right\} \\
& C(D)=C_{1}(D) \cup C_{2}(D) \cup C_{3}(D) \cup C_{4}(D) \\
& C_{0}^{\prime}(D)=\left\{\left\{Z_{4}, Z_{3}, Z_{1}\right\}\right\} \\
& C_{1}^{\prime}(D)=\left\{\left\{Z_{4}, Z_{3}, Z_{1}, \breve{D}\right\}\right\} \text {. } \\
& \text { and }\left|I_{D}\right|=\left|I_{C_{1}(D)}\right|+\left|I_{C_{2}(D)}\right|+\left|I_{C_{3}(D)}\right|+\left|I_{C_{4}(D)}\right|+\left|I_{C_{0}^{\prime}(D)}\right|+\left|I_{C_{1}^{\prime}(D)}\right| \text {, where }
\end{aligned}
$$

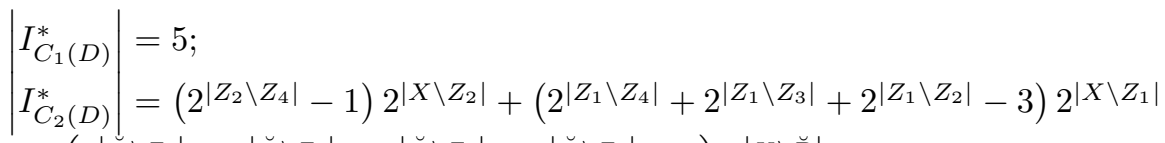$$
+\left(2^{\left|\breve{D} \backslash Z_{4}\right|}+2^{\left|\breve{D} \backslash Z_{3}\right|}+2^{\left|\breve{D} \backslash Z_{2}\right|}+2^{\left|\breve{D} \backslash Z_{1}\right|}-4\right) 2^{|X \backslash \breve{D}|}
$$$$
\left|I_{C_{3}(D)}^{*}\right|=\left(2^{\left|Z_{1} \backslash Z_{2}\right|}-1\right)\left(3^{\left|\breve{D} \backslash Z_{1}\right|}-2^{\left|\breve{D} \backslash Z_{1}\right|}\right) 3^{|X \backslash \breve{D}|}+\left(2^{\left|Z_{1} \backslash Z_{4}\right|}-1\right)+\left(2^{\left|Z_{1} \backslash Z_{4}\right|}-1\right)
$$$$
\left(3^{\left|\breve{D} \backslash Z_{1}\right|}-2^{\left|\breve{D} \backslash Z_{1}\right|}\right) 3^{|X \backslash \breve{D}|}+\left(2^{\left|Z_{2} \backslash Z_{4}\right|}-1\right)\left(3^{\left|\breve{D} \backslash Z_{2}\right|}-2^{\left|\breve{D} \backslash Z_{2}\right|}\right) 3^{|X \backslash \breve{D}|}
$$$$
+\left(2^{\left|Z_{2} \backslash Z_{4}\right|}-1\right)\left(3^{\left|Z_{1} \backslash Z_{2}\right|}-2^{\left|Z_{1} \backslash Z_{2}\right|}\right) 3^{\left|X \backslash Z_{1}\right|}+\left(2^{\left|Z_{1} \backslash Z_{3}\right|}-1\right)\left(3^{\left|\breve{D} \backslash Z_{1}\right|}-2^{\left|\breve{D} \backslash Z_{2}\right|}\right) 3^{|X \backslash \breve{D}|}
$$

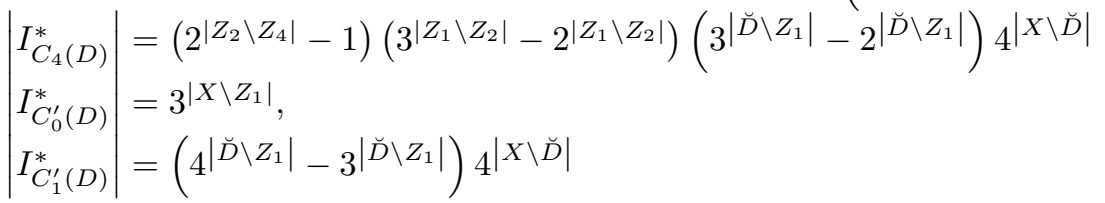

(see Theorems 2.11 and 2.15).

If $X=\{1,2,3,4\}, D=\{\{3\},\{2,4\},\{3,4\},\{2,3,4\},\{1,2,3,4\}\}$ then $\left|I_{C_{1}(D)}^{*}\right|=$ $5,\left|I_{C_{2}(D)}^{*}\right|=28,\left|I_{C_{3}(D)}^{*}\right|=13,\left|I_{C_{4}(D)}^{*}\right|=1,\left|I_{C_{0}^{\prime}(D)}^{*}\right|=3,\left|I_{C_{1}^{\prime}(D)}^{*}\right|=1,\left|I_{D}\right|=51$.

Example 3. Let $D=\left\{Z_{5}, Z_{4}, Z_{3}, Z_{2}, Z_{1}, \breve{D}\right\}$ be $Z_{1}$-elementary $X$-semilattice of unions satisfying the conditions

$$
\begin{aligned}
& Z_{5} \subset Z_{2} \subset Z_{1} \subset \breve{D}, Z_{5} \subset Z_{4} \subset Z_{1} \subset \breve{D}, Z_{3} \subset Z_{1} \subset \breve{D} Z_{4} \backslash Z_{3} \neq \emptyset \\
& Z_{3} \backslash Z_{4} \neq \emptyset, Z_{4} \backslash Z_{2} \neq \emptyset, Z_{2} \backslash Z_{4} \neq \emptyset, Z_{3} \backslash Z_{2} \neq \emptyset, Z_{2} \backslash Z_{3} \neq \emptyset \\
& Z_{4} \cup Z_{3}=Z_{4} \cup Z_{2}=Z_{3} \cup Z_{2}=Z_{5} \cup Z_{3}=Z_{1} .
\end{aligned}
$$

The semilattice satisfying the conditions (2.2) is shown in Fig. 2.9.

Let $C(D)=\left\{P_{0}, P_{1}, P_{2}, P_{3}, P_{4}, P_{5}\right\}$ be a family sets, where $P_{0}, P_{1}, P_{2}, P_{3}, P_{4}, P_{5}$ are pairwise disjoint subsets of the set $X$ and

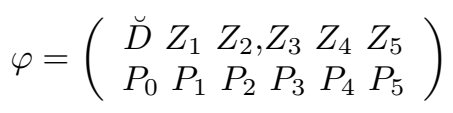

be a mapping of the semilattice $D$ onto the family sets $C(D)$. Then for the formal equalities of the semilattice $D$ we have a form:

$$
\begin{aligned}
& \breve{D}=P_{0} \cup P_{1} \cup P_{2} \cup P_{3} \cup P_{4} \cup P_{5} \\
& Z_{1}=P_{0} \cup P_{2} \cup P_{3} \cup P_{4} \cup P_{5} \\
& Z_{2}=P_{0} \cup P_{3} \cup P_{4} \cup P_{5}
\end{aligned}
$$




$$
\begin{aligned}
& Z_{3}=P_{0} \cup P_{2} \cup P_{4} \cup P_{5} \\
& Z_{4}=P_{0} \cup P_{2} \cup P_{3} \cup P_{5} \\
& Z_{5}=P_{0} \cup P_{3} .
\end{aligned}
$$

Here the elements $P_{1}, P_{2}, P_{3}, P_{4}$ are basic sources; the elements $P_{0}, P_{5}$ are sources of completeness of the $Z_{1}$-elementary $X$-semilattice of unions $D$.

Further, we have $Z_{5} \cap Z_{3}=\left(P_{0} \cup P_{3}\right) \cap\left(P_{0} \cup P_{2} \cup P_{4} \cup P_{5}\right)=P_{0}$.

(1) If $Z_{5} \cap Z_{3} \neq \emptyset\left(P_{0} \neq \emptyset\right)$, then $\mu=\emptyset, \nu=\left\{\left(Z_{5}, Z_{4}, Z_{2}\right)\right\}, h(D)=4, s=0,1$, $C_{1}(D)=\left\{\left\{Z_{5}\right\},\left\{Z_{4}\right\},\left\{Z_{3}\right\},\left\{Z_{2}\right\},\left\{Z_{1}\right\},\{\breve{D}\}\right\}$

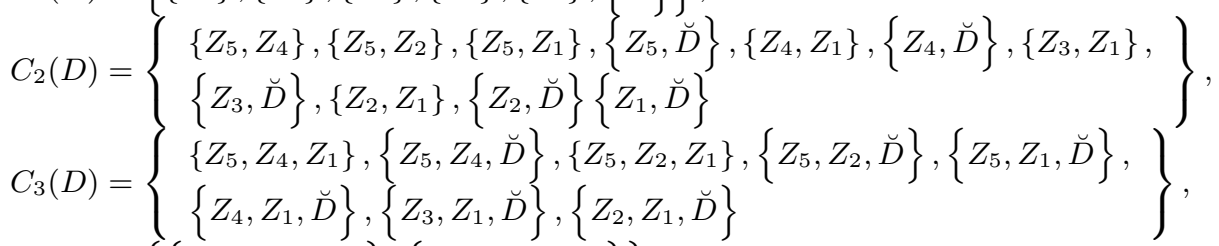

$C_{4}(D)=\left\{\left\{Z_{5}, Z_{4}, Z_{1}, \breve{D}\right\},\left\{Z_{5}, Z_{2}, Z_{1}, \breve{D}\right\}\right\}$

$C_{0}^{\prime \prime}(D)=\left\{\left\{Z_{5}, Z_{4}, Z_{2}, Z_{1}\right\}\right\}$

$C_{1}^{\prime \prime}(D)=\left\{\left\{Z_{5}, Z_{4}, Z_{2}, Z_{1}, \breve{D}\right\}\right\}$

$C(D)=C_{1}(D) \cup C_{2}(D) \cup C_{3}(D) \cup C_{4}(D), C^{\prime \prime}(D)=C_{0}^{\prime \prime}(D) \cup C_{1}^{\prime \prime}(D)$.

and $\left|I_{D}\right|=\left|I_{C_{1}(D)}\right|+\left|I_{C_{2}(D)}\right|+\left|I_{C_{3}(D)}\right|+\left|I_{C_{4}(D)}\right|+\left|I_{C_{0}^{\prime \prime}(D)}\right|+\left|I_{C_{1}^{\prime \prime}(D)}\right|$, where

$\left|I_{C_{1}(D)}^{*}\right|=6$;

$\left|I_{C_{2}(D)}^{*}\right|=\left(2^{\left|Z_{1} \backslash Z_{5}\right|}+2^{\left|Z_{1} \backslash Z_{4}\right|}+2^{\left|Z_{1} \backslash Z_{3}\right|}+2^{\left|Z_{1} \backslash Z_{2}\right|}-4\right) 2^{\left|X \backslash Z_{1}\right|}+\left(2^{\left|Z_{2} \backslash Z_{5}\right|}-1\right) 2^{\left|X \backslash Z_{1}\right|}$ $+\left(2^{\left|Z_{4} \backslash Z_{5}\right|}-1\right) 2^{\left|X \backslash Z_{4}\right|}+\left(2^{\left|\breve{D} \backslash Z_{5}\right|}+2^{\left|\breve{D} \backslash Z_{4}\right|}+2^{\left|\breve{D} \backslash Z_{3}\right|}+2^{\left|\breve{D} \backslash Z_{2}\right|}+2^{\left|\breve{D} \backslash Z_{1}\right|}-5\right) 2^{|X \backslash \breve{D}|} ;$ $\left|I_{C_{3}(D)}^{*}\right|=\left(2^{\left|Z_{4} \backslash Z_{5}\right|}-1\right)\left(3^{\left|Z_{1} \backslash Z_{4}\right|}-2^{\left|Z_{1} \backslash Z_{4}\right|}\right) 3^{\left|X \backslash Z_{1}\right|}$

$+\left(2^{\left|Z_{2} \backslash Z_{5}\right|}-1\right)\left(3^{\left|\breve{D} \backslash Z_{2}\right|}-2^{\left|\breve{D} \backslash Z_{2}\right|}\right) 3^{|X \backslash \breve{D}|}+\left(2^{\left|Z_{2} \backslash Z_{5}\right|}-1\right)\left(3^{\left|Z_{1} \backslash Z_{2}\right|}-2^{\left|Z_{1} \backslash Z_{2}\right|}\right) 3^{\left|X \backslash Z_{1}\right|}$ $+\left(2^{\left|Z_{2} \backslash Z_{5}\right|}-1\right)\left(3^{\left|\breve{D} \backslash Z_{2}\right|}-2^{\left|\breve{D} \backslash Z_{2}\right|}\right) 3^{|X \backslash \breve{D}|}+\left(2^{\left|Z_{1} \backslash Z_{5}\right|}-1\right)\left(3^{\left|\breve{D} \backslash Z_{1}\right|}-2^{\left|\breve{D} \backslash Z_{1}\right|}\right) 3^{|X \backslash \breve{D}|}$ $+\left(2^{\left|Z_{1} \backslash Z_{4}\right|}-1\right)\left(3^{\left|\breve{D} \backslash Z_{1}\right|}-2^{\left|\breve{D} \backslash Z_{1}\right|}\right) 3^{|x \backslash \breve{D}|}+\left(2^{\left|Z_{1} \backslash Z_{3}\right|}-1\right)\left(3^{\left|\breve{D} \backslash Z_{1}\right|}-2^{\left|\breve{D} \backslash Z_{1}\right|}\right) 3^{|X \backslash \breve{D}|}$ $+\left(2^{\left|Z_{1} \backslash Z_{2}\right|}-1\right)\left(3^{\left|\breve{D} \backslash Z_{1}\right|}-2^{\left|\breve{D} \backslash Z_{1}\right|}\right) 3^{|X \backslash \breve{D}|} ;$

$\left|I_{C_{4}(D)}^{*}\right|=\left(2^{\left|Z_{4} \backslash Z_{5}\right|}-1\right)\left(3^{\left|Z_{1} \backslash Z_{4}\right|}-2^{\left|Z_{1} \backslash Z_{4}\right|}\right)\left(3^{\left|\breve{D} \backslash Z_{1}\right|}-2^{\left|\breve{D} \backslash Z_{1}\right|}\right) 4^{|X \backslash \breve{D}|}$ $+\left(2^{\left|Z_{2} \backslash Z_{5}\right|}-1\right)\left(3^{\left|Z_{1} \backslash Z_{2}\right|}-2^{\left|Z_{1} \backslash Z_{2}\right|}\right)\left(3^{\left|\breve{D} \backslash Z_{1}\right|}-2^{\left|\breve{D} \backslash Z_{1}\right|}\right) 4^{|X \backslash \breve{D}|}$

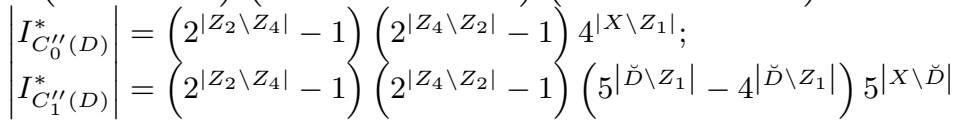

(see Theorems 2.11 and 2.18).

If $X=\{1,2,3,4,5,6\}$,

$D=\{\{3,6\},\{2,3,5,6\},\{2,4,5,6\},\{3,4,5,6\},\{2,3,4,5,6\},\{1,2,3,4,5,6\}\}$

then $\left|I_{C_{1}(D)}^{*}\right|=6,\left|I_{C_{2}(D)}^{*}\right|=69,\left|I_{C_{3}(D)}^{*}\right|=58,\left|I_{C_{4}(D)}^{*}\right|=6,\left|I_{C_{0}^{\prime \prime}(D)}^{*}\right|=4$, $\left|I_{C_{1}^{\prime \prime}(D)}^{*}\right|=1,\left|I_{D}\right|=144$. 
(2) If $Z_{5} \cap Z_{3}=\emptyset\left(P_{0}=\emptyset\right)$, then $\mu=\left\{\left(Z_{5}, Z_{3}\right)\right\}, \nu=\left\{\left(Z_{5}, Z_{2}, Z_{4}\right)\right\}, h(D)=4$, $s=0,1$,

$$
\begin{aligned}
& C_{1}(D)=\left\{\left\{Z_{5}\right\},\left\{Z_{4}\right\},\left\{Z_{3}\right\},\left\{Z_{2}\right\},\left\{Z_{1}\right\},\{\breve{D}\}\right\}, \\
& C_{2}(D)=\left\{\begin{array}{l}
\left\{Z_{5}, Z_{2}\right\},\left\{Z_{5}, Z_{4}\right\},\left\{Z_{5}, Z_{1}\right\},\left\{Z_{5}, \breve{D}\right\},\left\{Z_{4}, Z_{1}\right\},\left\{Z_{4}, \breve{D}\right\},\left\{Z_{3}, Z_{1}\right\}, \\
\left\{Z_{3}, \breve{D}\right\},\left\{Z_{2}, Z_{1}\right\},\left\{Z_{2}, \breve{D}\right\}\left\{Z_{1}, \breve{D}\right\}
\end{array}\right\}, \\
& C_{3}(D)=\left\{\begin{array}{l}
\left\{Z_{5}, Z_{4}, Z_{1}\right\},\left\{Z_{5}, Z_{4}, \breve{D}\right\},\left\{Z_{5}, Z_{2}, Z_{1}\right\},\left\{Z_{5}, Z_{2}, \breve{D}\right\},\left\{Z_{5}, Z_{1}, \breve{D}\right\}, \\
\left\{Z_{4}, Z_{1}, \breve{D}\right\},\left\{Z_{3}, Z_{1}, \breve{D}\right\},\left\{Z_{2}, Z_{1}, \breve{D}\right\}
\end{array}\right\}, \\
& C_{4}(D)=\left\{\left\{Z_{5}, Z_{4}, Z_{1}, \breve{D}\right\},\left\{Z_{5}, Z_{2}, Z_{1}, \breve{D}\right\}\right\}, \\
& C_{0}^{\prime \prime}(D)=\left\{\left\{Z_{5}, Z_{3}, Z_{1}\right\}\right\}, C_{1}^{\prime \prime}(D)=\left\{\left\{Z_{5}, Z_{3}, Z_{1}, \breve{D}\right\}\right\}, \\
& C_{0}^{\prime \prime}(D)=\left\{\left\{Z_{5}, Z_{4}, Z_{2}, Z_{1}\right\}\right\}, C_{1}^{\prime \prime}(D)=\left\{\left\{Z_{5}, Z_{4}, Z_{2}, Z_{1}, \breve{D}\right\}\right\}, \\
& C(D)=C_{1}(D) \cup C_{2}(D) \cup C_{3}(D) \cup C_{4}(D), \\
& C^{\prime}(D)=C_{0}^{\prime}(D) \cup C_{1}^{\prime}(D), \quad C^{\prime \prime}(D)=C_{0}^{\prime \prime}(D) \cup C_{1}^{\prime \prime}(D)
\end{aligned}
$$

and $\left|I_{D}\right|=\left|I_{C_{1}(D)}\right|+\left|I_{C_{2}(D)}\right|+\left|I_{C_{3}(D)}\right|+\left|I_{C_{4}(D)}\right|+\left|I_{C_{0}^{\prime}(D)}\right|+\left|I_{C_{1}^{\prime}(D)}\right|+\left|I_{C_{0}^{\prime \prime}(D)}\right|+$ $\left|I_{C_{1}^{\prime \prime}(D)}\right|$, where

$$
\begin{aligned}
& \left|I_{C_{1}(D)}^{*}\right|=6 ; \\
& \mid I_{C_{2}(D)}^{*}=\left(2^{\left|Z_{1} \backslash Z_{5}\right|}+2^{\left|Z_{1} \backslash Z_{4}\right|}+2^{\left|Z_{1} \backslash Z_{3}\right|}+2^{\left|Z_{1} \backslash Z_{2}\right|}-4\right) 2^{\left|X \backslash Z_{1}\right|}+\left(2^{\left|Z_{2} \backslash Z_{5}\right|}-1\right) 2^{\left|X \backslash Z_{1}\right|} \\
& +\left(2^{\left|Z_{4} \backslash Z_{5}\right|}-1\right) 2^{\left|X \backslash Z_{4}\right|}+\left(2^{\left|\breve{D} \backslash Z_{5}\right|}+2^{\left|\breve{D} \backslash Z_{4}\right|}+2^{\left|\breve{D} \backslash Z_{3}\right|}+2^{\left|\breve{D} \backslash Z_{2}\right|}+2^{\left|\breve{D} \backslash Z_{1}\right|}-5\right) 2^{|X \backslash \breve{D}|} ; \\
& \mid I_{C_{3}(D)}^{*}=\left(2^{\left|Z_{4} \backslash Z_{5}\right|}-1\right)\left(3^{\left|Z_{1} \backslash Z_{4}\right|}-2^{\left|Z_{1} \backslash Z_{4}\right|}\right) 3^{\left|X \backslash Z_{1}\right|} \\
& +\left(2^{\left|Z_{2} \backslash Z_{5}\right|}-1\right)\left(3^{\left|\breve{D} \backslash Z_{2}\right|}-2^{\left|\breve{D} \backslash Z_{2}\right|}\right) 3^{|X \backslash \breve{D}|}+\left(2^{\left|Z_{2} \backslash Z_{5}\right|}-1\right)\left(3^{\left|Z_{1} \backslash Z_{2}\right|}-2^{\left|Z_{1} \backslash Z_{2}\right|}\right) 3^{\left|X \backslash Z_{1}\right|} \\
& +\left(2^{\left|Z_{2} \backslash Z_{5}\right|}-1\right)\left(3^{\left|\breve{D} \backslash Z_{2}\right|}-2^{\left|\breve{D} \backslash Z_{2}\right|}\right) 3^{|X \backslash \breve{D}|}+\left(2^{\left|Z_{1} \backslash Z_{5}\right|}-1\right)\left(3^{\left|\breve{D} \backslash Z_{1}\right|}-2^{\left|\breve{D} \backslash Z_{1}\right|}\right) 3^{|X \backslash \breve{D}|} \\
& +\left(2^{\left|Z_{1} \backslash Z_{4}\right|}-1\right)\left(3^{\left|\breve{D} \backslash Z_{1}\right|}-2^{\left|\breve{D} \backslash Z_{1}\right|}\right) 3^{|X \backslash \breve{D}|}+\left(2^{\left|Z_{1} \backslash Z_{3}\right|}-1\right)\left(3^{\left|\breve{D} \backslash Z_{1}\right|}-2^{\left|\breve{D} \backslash Z_{1}\right|}\right) 3^{|X \backslash \breve{D}|} \\
& +\left(2^{\left|Z_{1} \backslash Z_{2}\right|}-1\right)\left(3^{\left|\breve{D} \backslash Z_{1}\right|}-2^{\left|\breve{D} \backslash Z_{1}\right|}\right) 3^{|X \backslash \breve{D}|} ; \\
& \mid I_{C_{4}(D)}^{*}=\left(2^{\left|Z_{4} \backslash Z_{5}\right|}-1\right)\left(3^{\left|Z_{1} \backslash Z_{4}\right|}-2^{\left|Z_{1} \backslash Z_{4}\right|}\right)\left(3^{\left|\breve{D} \backslash Z_{1}\right|}-2^{\left|\breve{D} \backslash Z_{1}\right|}\right) 4^{|X \backslash \breve{D}|} \\
& +\left(2^{\left|Z_{2} \backslash Z_{5}\right|}-1\right)\left(3^{\left|Z_{1} \backslash Z_{2}\right|}-2^{\left|Z_{1} \backslash Z_{2}\right|}\right)\left(3^{\left|\breve{D} \backslash Z_{1}\right|}-2^{\left|\breve{D} \backslash Z_{1}\right|}\right) 4^{|X \backslash \breve{D}|} \\
& \left|I_{C_{0}^{\prime}(D)}^{*}\right|=3^{\left|X \backslash Z_{1}\right|},\left|I_{C_{1}^{\prime}(D)}^{*}\right|=\left(4^{\left|\breve{D} \backslash Z_{1}\right|}-3^{\left|\breve{D} \backslash Z_{1}\right|}\right) 4^{|X \backslash \breve{D}|} \\
& I_{C_{0}^{\prime \prime}(D)}^{*} \mid=\left(2^{\left|Z_{2} \backslash Z_{4}\right|}-1\right)\left(2^{\left|Z_{4} \backslash Z_{2}\right|}-1\right) 4^{\left|X \backslash Z_{1}\right|}, \\
& I_{C_{1}^{\prime \prime}(D)}^{*} \mid=\left(2^{\left|Z_{2} \backslash Z_{4}\right|}-1\right)\left(2^{\left|Z_{4} \backslash Z_{2}\right|}-1\right)\left(5^{\left|\breve{D} \backslash Z_{1}\right|}-4^{\left|\breve{D} \backslash Z_{1}\right|}\right) 5^{|X \backslash \breve{D}|}
\end{aligned}
$$

(see Theorems 2.11, 2.15 and 2.18).

If $X=\{1,2,3,4,5\}$,

$$
D=\{\{3\},\{2,3,5\},\{2,4,5\},\{3,4,5\},\{2,3,4,5\},\{1,2,3,4,5\}\}
$$

$$
\begin{aligned}
& \text { then }\left|I_{C_{1}(D)}^{*}\right|=6,\left|I_{C_{2}(D)}^{*}\right|=69,\left|I_{C_{3}(D)}^{*}\right|=58,\left|I_{C_{4}(D)}^{*}\right|=6,\left|I_{C_{0}^{\prime}(D)}^{*}\right|=3, \\
& \left|I_{C_{1}^{\prime}(D)}^{*}\right|=1,\left|I_{C_{0}^{\prime \prime}(D)}^{*}\right|=4,\left|I_{C_{1}^{\prime \prime}(D)}^{*}\right|=1,\left|I_{D}\right|=148 .
\end{aligned}
$$




\section{REFERENCES}

[1] Ya. Diasamidze and Sh. Makharadze, Complete Semigroups of Binary Relations, İstanbul, Kriter Yayınevi, ISBN: 978-605-4613, 2013, 524p.

[2] Ya. I. Diasamidze, Complete Semigroups of Binary Relations, J. Math. Sci., Plenum Publishing Corporation, New York, 117 (4) (2003), 4271-4319.

[3] Ya. Diasamidze, Sh. Makharadze, G. Partenadze and O. Givradze, On finite X-semilattices of unions, J. Math. Sci., Plenum Publishing Corporation, New York, 141(4) (2007), 1134-1181.

[4] Ya. Diasamidze and Sh. Makharadze, Maximal subgroups of complete semigroups of binary relations, Proc. A. Razmadze Math. Inst., 131 (2003), 21-38.

[5] Ya. Diasamidze, Sh. Makharadze and Il. Diasamidze, Idempotents and regular elements of complete semigroups of binary relations, J. Math. Sci., Plenum Publshing Corporation, New York, 153 (4) (2008), 481-499.

[6] Ya. Diasamidze, Sh. Makharadze and N. Rokva, On XI-semilattices of union, Bull. Georg. Nation. Acad. Sci., 2 (1) (2008), 16-24.

(Received: April 9, 2014)

(Revised: October 1, 2014)
I. Ya. Diasamidze and Sh. Makharadze

Shota Rustaveli State University

35, Ninoshvili St., Batumi 6010

Georgia

Neşet Aydın

Canakkale Onsekiz Mart University

Department of Mathematics

Canakkale, Turkey

neseta@comu.edu.tr

http://www.comu.edu.tr

Ali Erdoğan

Hacettepe University

Department of Mathematics

Ankara, Turkey

http://www.hacettepe.edu.tr 